\title{
SOEP
}

SOEPpapers

on Multidisciplinary Panel Data Research

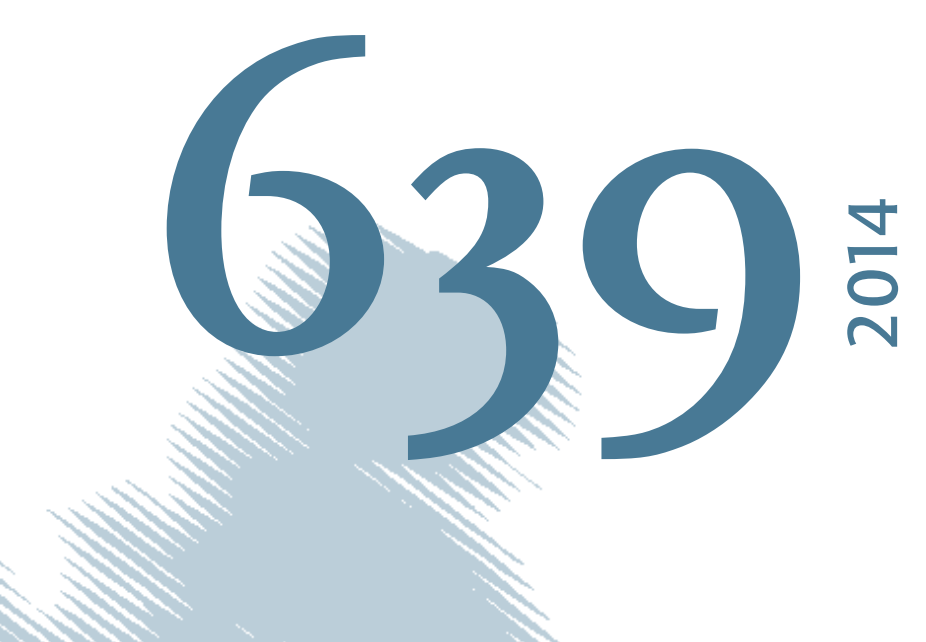

\section{Dissatisfied with Life or with Being Interviewed? Happiness and Motivation to Participate in a Survey}




\section{SOEPpapers on Multidisciplinary Panel Data Research}

at DIW Berlin

This series presents research findings based either directly on data from the German SocioEconomic Panel Study (SOEP) or using SOEP data as part of an internationally comparable data set (e.g. CNEF, ECHP, LIS, LWS, CHER/PACO). SOEP is a truly multidisciplinary household panel study covering a wide range of social and behavioral sciences: economics, sociology, psychology, survey methodology, econometrics and applied statistics, educational science, political science, public health, behavioral genetics, demography, geography, and sport science.

The decision to publish a submission in SOEPpapers is made by a board of editors chosen by the DIW Berlin to represent the wide range of disciplines covered by SOEP. There is no external referee process and papers are either accepted or rejected without revision. Papers appear in this series as works in progress and may also appear elsewhere. They often represent preliminary studies and are circulated to encourage discussion. Citation of such a paper should account for its provisional character. A revised version may be requested from the author directly.

Any opinions expressed in this series are those of the author(s) and not those of DIW Berlin. Research disseminated by DIW Berlin may include views on public policy issues, but the institute itself takes no institutional policy positions.

The SOEPpapers are available at

http://www.diw.de/soeppapers

\section{Editors:}

Jürgen Schupp (Sociology)

Gert G. Wagner (Social Sciences, Vice Dean DIW Graduate Center)

Conchita D'Ambrosio (Public Economics)

Denis Gerstorf (Psychology, DIW Research Director)

Elke Holst (Gender Studies, DIW Research Director)

Frauke Kreuter (Survey Methodology, DIW Research Professor)

Martin Kroh (Political Science and Survey Methodology)

Frieder R. Lang (Psychology, DIW Research Professor)

Henning Lohmann (Sociology, DIW Research Professor)

Jörg-Peter Schräpler (Survey Methodology, DIW Research Professor)

Thomas Siedler (Empirical Economics)

C. Katharina Spieß (Empirical Economics and Educational Science)

ISSN: 1864-6689 (online)

German Socio-Economic Panel Study (SOEP)

DIW Berlin

Mohrenstrasse 58

10117 Berlin, Germany

Contact: Uta Rahmann | soeppapers@diw.de 


\title{
Dissatisfied with Life or with Being Interviewed? Happiness and Motivation to Participate in a Survey
}

\author{
Adrian Chadi \\ Institute for Labour Law and Industrial Relations in the European Union (IAAEU) \\ University of Trier, 54286 Trier, Germany \\ Tel: +49651 201 4774, Fax: +49651 2014742 \\ Email: chadi@iaaeu.de
}

\begin{abstract}
Information on the number of interviewer contacts allows insights into how people's responses to questions on happiness are connected to the difficulty of reaching potential participants. Using the paradata of the German Socio-Economic Panel Study (SOEP), this paper continues such research by revealing a strong link between respondent motivation and reported happiness. Analyses of responses by future non-respondents substantiate this finding and shed light on a key question for empirical research on subjective well-being, which is whether the unhappy tend to avoid survey participation or whether the unwilling might respond more negatively when being asked about their satisfaction with life.
\end{abstract}

\section{JEL Classification Codes}

C8, I3

\section{Keywords}

Happiness, Respondent motivation, Measurement bias, Life satisfaction, Panel attrition, Interviewer contacts

Acknowledgements: I am grateful to Peter Krause and Martin Kroh for very helpful advice. For comments and discussions, I thank Daniel Arnold as well as the participants of the $10^{\text {th }}$ International SOEP User Conference, Berlin 2012, the CISEPS International Conference on Public Happiness, Rome 2013, the $12^{\text {th }}$ TIBER Conference, Tilburg 2013, the IAAEU seminar, Trier 2013, and the Statistical Week of the German Statistical Society, Berlin 2013. 


\section{Introduction}

Survey response phenomena are becoming a major concern for empirical researchers of happiness data. Especially among economists, issues like interview mode (Conti and Pudney 2011) or time in panel (Chadi 2013a) are increasingly being looked at, and many recent studies consider survey factors in the analysis of well-being. ${ }^{1}$ The discussion on data validity primarily focuses on observable information, while less attention is given to the issue of nonresponse and people's motivation to participate in a survey. As a novel idea in this context, Heffetz and Rabin (2013) demonstrate how technical information can be exploited for research on those who were almost not included in the survey data. Using the number of contact attempts, they find remarkable differences in reported happiness among difficult-toreach respondents when comparing sub-groups like males and females, which indicates how conclusions may depend on the composition of the data and thus on the issue of non-response. The present paper continues this kind of research into the validity of happiness data obtained in surveys by exploiting the paradata of the German Socio-Economic Panel Study (SOEP), which is a large panel data set that is widely used in the happiness field. While available information on interviewer contacts allows re-examination of the role of people's reachability in a second data set, the main part of the investigation here goes deeper into the analysis of why some people are hard to reach. The idea is that one reason for a higher number of interviewer contacts is people's unwillingness to do the interview, which can be revealed after controlling for other determinants of people's reachability. The prime research objective is to analyze a potential link between life satisfaction and respondent motivation, which is thereby introduced as a new aspect to the literature on well-being and survey methodology.

The evidence from applying multiple regression analyses confirms a negative effect of higher numbers of interviewer contacts on reported happiness, which, similar to the data used by Heffetz and Rabin, does not appear in the average values. To substantiate the role of respondent motivation, the book-keeping information of the data collecting agency is exploited further. In fact, over a time span of five years, interviewers were asked about their perception of respondents' willingness to participate. The empirical results show that this variable is even more strongly connected to self-reported happiness, while due to its consideration the interviewer contact effect diminishes. This suggests that both variables indicate differences in respondent motivation, which are connected to life satisfaction

\footnotetext{
${ }^{1}$ See e.g. d'Ambrosio and Frick (2012), Frijters and Beatton (2012), Wunder et al. (2013) and Baetschmann (forthcoming). Alternatively, survey aspects like the day of the interview (Taylor 2006) have recently been exploited as instruments for well-being (Wunder and Heineck 2013) and as the basis for quasi-experimental investigations of people’s well-being using panel data (e.g. Metcalfe et al. 2011, Goebel et al. 2013).
} 
responses in such a way that less willingness is linked to lower reported well-being. Applying this basic finding to the important issue of panel attrition, the empirical analysis continues by using non-response as another expression of unwillingness. Studying happiness responses of those who are about to leave the panel confirms the expectation of a negative effect linked to a third indicator of low respondent motivation.

There are two plausible explanations for the link between people's motivation to participate in a survey and their self-reported happiness. The first is sample selectivity, which means those who are reluctant in doing the interview are in fact inherently unhappy. This seems particularly likely for older people with bad health conditions. A second explanation refers to a novel and thus unknown bias phenomenon of more negative responses from less willing participants, which may come from differences in attitudes towards the interview itself. To investigate deeper whether there is such a causal effect of respondent motivation on selfreported happiness, the final empirical part exploits the panel phenomenon of interviewer attrition as an instrument for interviewee attrition. Worrying to survey organizers but useful in the present context, there is a well-known attrition problem when already unwilling people are asked to continue in the panel by a different person than before. The "conventional wisdom" (Watson and Wooden forthcoming) says that such a request is more easily rejected when there is a change in the person asking for the interview, which necessarily happens when an interviewer e.g. stops working for the data collecting agency. This exogenous event from the perspective of the potential interviewee provides a relevant but also valid instrument, as there is no separate effect from subsequent interviewer attrition on respondent's well-being in their last year of participation. The causal evidence revealed by applying such an instrumental variable approach supports the second explanation and hence the existence of a measurement bias caused by people's unwillingness to participate in a survey.

The paper is structured as follows. The following section discusses previous research that is relevant for the research idea to study respondent motivation in the context of happiness analyses. Section 3 introduces the data set used and illustrates the empirical strategy. The empirical analysis in Section 4 starts with a brief discussion of the difficult-to-reach factor in the vein of Heffetz and Rabin and then moves on to examine the role of respondent motivation in happiness data, which includes results from using information on interviewer contacts, interviewee assessments by the interviewers, and actual non-response. The final Section 5 concludes and discusses the findings. 


\section{Response Behavior and Self-Reported Well-Being}

Research on people's well-being commonly takes place on the basis of data obtained in surveys, in which interviewees are asked to evaluate their life on satisfaction scales. ${ }^{2}$ As the assessment of one's life is a complex challenge, survey methodology research has always been interested in whether subjective well-being can be measured reliably in such a way. Interestingly, many scholars come to the conclusion that there are no major problems with simply asking people about their life satisfaction and using the data obtained (see Frey and Stutzer 2002). Obviously, one facet of the debate on validity of happiness data is its interdisciplinarity. Since economists are late-comers to the subject of happiness, they are also late-comers to the discussion of data validity. Yet, the recent wave of research into the issue comes mainly from the economic discipline and has already led to new and important insights (e.g. Pudney 2011, Kassenboehmer and Haisken-DeNew 2012, Chadi 2013b, Tumen and Zeydanli forthcoming). Large panel data sets and available empirical tools allow the detection of response artefacts and their causes, which are important issues well-being researchers need to be aware of. Contrariwise, only little is known about the role of happiness in the context of non-response, despite the fact that panel surveys usually suffer under significant attrition. Not mentioning attrition problems implies that researchers implicitly assume similarity between survey participants and non-respondents, which often appears to be a questionable assumption. Even if available weighting factors are used to deal with panel attrition, implications regarding the analysis of well-being determinants are rather unclear. Moreover, whereas some researchers refer to the high response rates of happiness questions, a satisfactory item response cannot mitigate the problem of missing data from those who refuse the interview completely. ${ }^{3}$

Previous studies that have contributed to reducing researchers' concerns with potential attrition problems in the context of well-being come from Smith (1984) who finds no significant distortions in the data, and Moum (1994). The latter exploits information on people who would typically be non-respondents in common surveys and interprets the findings as "good news for survey researchers working with self-report measures of well-being." Thus, similar to Smith (1984) he confirms the "pleasant finding” of no serious refusal bias. A deeper

\footnotetext{
${ }^{2}$ This paper focuses on data obtained from a cognitive measure of people’s happiness. The terms life satisfaction and subjective well-being are used synonymously. An affective measure of people's happiness in recent time plays a minor role. See Schimmack (2009) for a SOEP-based discussion of different well-being measures.

${ }^{3}$ In the context of income analyses, researchers are usually more aware of problems related to non-response, as lower and very high income receivers are more difficult to be included in the data collection process. Yet, even for attrition problems related to income levels the evidence is actually quite mixed. See Watson (2003) who discovers for some countries in the European Community Household Panel a tendency to lose people either from the top or the bottom of the income distribution. See also Becketti et al. (1988), Hill and Willis (2001), Meyer and Sullivan (2003) as well as Nicoletti et al. (2011).
} 
look into the existing literature leads to even earlier work, such as Sobol's (1959) study into a potential attrition of pessimistic people, but also to research from different fields, such as Norris' (1985) contribution to gerontology research. While there is at least some evidence for an unhappiness-attrition link, the latter study raises the question of whether it is rather (bad) health than life satisfaction itself that may trigger non-response. While for panel attrition researchers, illness might appear as a typical determinant of non-response, most applied researchers are not very concerned with a refusal bias related to people’s well-being, despite recent evidence for such a problem.

Wooden and Li (forthcoming) find for Australian panel data that an indicator variable for participants who are not part of the next survey wave has a significantly negative coefficient in life satisfaction models. ${ }^{4}$ While the authors are primarily interested in the role of panel conditioning, they do not look closer at this finding which they interpret as evidence for sample selectivity. Note that panel surveys typically have associated researchers who are looking at the issue of attrition, simply due to the fact that weighting factors are needed. In contrast to the Australian data, Uhrig (2008) does not report on life satisfaction as a determinant of attrition in the British Household Panel Study (BHPS), whereas in the Swiss Household Panel (SHP) survey, the evidence suggests a link between individual life satisfaction and the probability of leaving the panel (Lipps 2007). In regard to the German SOEP, the attrition of unhappy people has not been a major concern so far, despite some evidence in the annually published SOEP data documentation, which for some survey waves does indeed show a link between well-being measures and non-response probability. ${ }^{5}$

An obvious explanation for the reluctance of happiness researchers to spend much time on people who do not participate in surveys is the lack of data about non-respondents. At that point, the idea of Heffetz and Rabin (2013) constitutes a novel approach to analyzing what might be missing in a data sample. Their study on the link between self-reported happiness and the reachability of respondents contributes to the research on the role of non-response in surveys. Beforehand, only scholars of survey methodology have discussed difficult-toconvince respondents by using information on the number of contacts with each potential

\footnotetext{
${ }^{4}$ In an earlier study, Wooden, the current director of the Household, Income and Labour Dynamics in Australia (HILDA) survey, and Watson (2004) already discuss how people with lower life satisfaction are more likely to leave the panel. However, the link loses significance the more control variables are introduced to the regression model, so that they conclude in that paper that considering attrition makes "very little difference to the estimation of our selected outcome variables" (such as life satisfaction).

${ }^{5}$ The recent data documentation on panel attrition in the SOEP considers the aspect of individual well-being as a predictor of (non-)response (Kroh 2012). Contrariwise, Kroh (2010) includes only life satisfaction expectations in the list of determinants, whereas the analysis a year earlier does not include any happiness-related measure (Kroh 2009). Meanwhile, health indicators are always included. Note that these annual documentations are based on cross-section analyses of response probabilities for the following survey wave.
} 
respondent. ${ }^{6}$ The contribution of Heffetz and Rabin is to apply this technical information to the specific subject of well-being measurement. Their most intriguing finding constitutes a gender gap in affective happiness that appears only among men and women who are difficult to reach. Vice versa, there is no significant difference between the genders in data that consists only of easily reachable people, which necessarily results from a survey policy that restricts attempts to contact interviewees. Thereby, the authors contribute to the debate on gender differences (e.g. Stevenson and Wolfers 2009) and show with their data from the Surveys of Consumers (SOC) how the effect of a happiness determinant may depend on rather technical survey aspects and people’s (non-)response behavior.

While Heffetz and Rabin use data on call attempts to discuss differences in respondent reachability, the present paper re-examines their approach with SOEP data but then goes further by investigating for the first time the role of respondent motivation in the analysis of happiness. The starting point is the idea that people's willingness to participate in a survey is one explanatory factor for their varying reachability, as it can be assumed that some of the harder-to-reach people simply do not want to be interviewed. While there are other determinants for differences in reachability, such as employment status, unwillingness to do the interview is the factor of interest here and is examined further regarding its link to reported well-being. For the same purpose, information on future non-response can be exploited as another indicator of interviewees' unwillingness.

One intuition behind the potential link between happiness and motivation to participate is that unhappier people select themselves out of panels. A second interpretation relates to a direct effect of unwillingness on the self-reported happiness of those participating. Accordingly, varying levels of motivation among respondents might trigger differences in responses. Olson (2013), for instance, points out that people who are "eventually convinced to participate” may show a different commitment to answering questions accurately. To illustrate the argument here, imagine two identical participants who are both equally happy with their lives but one is willing to do the interview and the other person dislikes being interviewed. Both are asked how satisfied they are with life in general. However, the second person is clearly annoyed and thereby negatively affected in this situation when doing the interview. The question is whether this person with the low motivation may bias responses downwards due to a feeling

\footnotetext{
${ }^{6}$ As an example, Kreuter et al. (2010) investigate data on benefit recipients and look at the role of number of calls. For a study on how potential refusals in the BHPS were persuaded via additional contact attempts, see Burton et al. (2006). For the HILDA survey, Watson and Wooden (2004, 2009) find a significant relationship between number of call attempts and subsequent attrition. They conclude that this contact information indicates current and future difficulty in reaching households by identifying "evasive" respondents. For a recent literature review on the effort needed to recruit respondents and potential implications for data quality, see Olson (2013).
} 
of discomfort and dissatisfaction with the interview situation itself, independent from their true level of happiness. If so, reported scores from that person may be too low, and would be measured incorrectly as a result of aversion towards the interview. Whereas some researchers mention the significance of a good and pleasant atmosphere (e.g. Nederhof 1987, Pickery et al. 2001) or even recommend keeping respondents "happy” when being interviewed (Olsen 2005), differences in the way interviewees perceive the experience of survey participation have not been investigated regarding its role for well-being measurement. The only indication for such a situation-specific effect so far comes from studying those individuals who skip questions at the end of the survey, as indication of aversion and low motivation. ${ }^{7}$ Hence, the following analysis examines the relationship between respondent motivation and happiness and thereby sheds light on the question of whether the described kind of negativity bias is a relevant phenomenon or whether true unhappiness works as a determinant of non-response.

\section{Data and Empirical Strategy}

The SOEP is Europe's longest running representative and ongoing panel survey of households (see Wagner et al., 2007). Year by year, thousands of participants are questioned about their lives either directly by the interviewers of the data collecting agency or via questionnaires that people can fill out on their own. The latter option is not the preferred choice according to the SOEP organizers, as data quality is expected to be better when interviewers and interviewees meet each other face to face. Another goal of the survey design is the maximization of response rates. In an ideal situation, interviewers reach all households the agency has assigned to them and conduct interviews with all adult household members. These attempts, whether successful or not, are documented by the agency, which collects information on the number of times an interviewer tries to reach a potential household. This variable corresponds to the information on call attempts in the SOC exploited by Heffetz and Rabin (2013), as well as to similar variables in other panels. Paradata of this kind and more is provided to the research community as an add-on to the standard data set made available by the SOEP. This additional information about the data collection process is part of the so-called "Brutto" files, which constitutes a, so far, only little recognized treasure trove for research purposes. The number of interviewer contacts is available for all waves, except for the initial wave of 1984, and for most of the participating households. ${ }^{8}$ According to the codebook for the "Brutto" data, this

\footnotetext{
${ }^{7}$ In the SOEP data, there is a significantly negative link between not responding to the second last question and the life satisfaction scores reported in the final question (Chadi 2012).

${ }^{8}$ When there is contact via mail only, so that questionnaires are filled out without interviewer presence, then there is usually no data available on the contact attempts. Thus, the survey mode of "self-written questionnaires by mail" has to be left out of the analysis. For some basic information on the interview modes, see Table A1.
} 
variable is a rough indicator for the effort provided by interviewers to realize the interviews in each household. The detailed information on the interviewer contacts ranges from "one contact" interviews to "nine contacts and more" interviews, which principally would allow the generation of the same categorization as in the graphical analysis in Heffetz and Rabin. Yet, due to differences in the distribution of reachability figures (when comparing SOEP and SOC data), the categorization chosen here differs from theirs. Many households are reached in the second attempt while, only for a minority of cases, more than six contacts are needed (see Appendix Table A2).

As Schraepler et al. (2010) point out in the only available SOEP study on interviewer contacts, there are several factors why people are "difficult to reach" such as household composition or being a middle-aged person. While health seems also significant, the use of objective health information is preferred here, as available subjective variables may be too closely related to subjective well-being. ${ }^{9}$ This decision restricts the first data sample (Set 1) to the period of 1995 to 2011. A key advantage of the SOEP paradata is that research on the link between respondent motivation and happiness responses can go beyond the exploitation of interviewer contacts as an indirect indicator. For the time period from 2002 to 2006, the SOEP "Brutto” file contains data from the interviewers who were asked to assess each interviewee’s willingness to participate. Since such direct information on respondent motivation is scarce, this appears to be a very attractive option, despite the subjective nature of this information. In contrast to the number of interviewer contacts, this SOEP variable is obtained on the individual level and has never been used for research purposes so far. Due to the availability of this variable, the sample for the corresponding part of the analysis (Set 2) is restricted to five waves (and is illustrated in the second column of Appendix Table A1, whereas the first column refers to the sample used for analyzing the role of interviewer contacts).

The next part of the analysis applies the insights from using direct and indirect measures of respondent motivation on the issue of actual non-response. The idea is that those who provide evidence for their unwillingness by ultimately refusing to do the interview already had a lower level of motivation a year earlier. Note that the most significant reason of non-response in the SOEP is refusal (Schraepler et al. 2010), just like in other surveys (e.g. Watson and Wooden 2004, Lipps 2009). A relevant aspect here is the distinction between those who leave the panel and cases of "re-engagement" (Watson and Wooden forthcoming) when interviewees refuse the interview in one year but continue to participate afterwards. A simple interpretation is that leaving forever is a stronger expression of unwillingness and the

\footnotetext{
${ }^{9}$ Three objective health indicators are available for every SOEP wave since 1995 and are shown in Table A1.
} 
temporary refusal is a milder expression of it. In order to identify the former, the two recent waves of 2010 and 2011 are used solely for the purpose of having "future" information on people's response behavior. In the SOEP data, the chances of a return are very low when someone refuses for two years in a row, so that all respondents who stopped participating in the SOEP survey in 2009 or earlier are considered as permanent panel leavers. ${ }^{10}$

To fully identify the potential effects of low respondent motivation years before someone drops out of the panel, the sample used for this part of the analysis is restricted further. For the purpose of examining not only the role of leaving in the year after, but also in two, three and four years in the future, the data is limited in such a way that the last wave examined in this part of the analysis is from 2006. This corresponds to another necessary restriction connected to the availability of variables that are important for understanding the link between (low) willingness of participating and life satisfaction responses. As pointed out above, health is likely to be connected to the refusal probability but also to the actual level of happiness. This is particularly true for people who are in very bad circumstances and are about to die, which of course also affects SOEP participants. ${ }^{11}$ The advice of Wagner et al. (2007) is to exploit the available "biography and life history" data, which was obtained for exactly these research purposes. By doing so, Gerstorf et al. (2010) find strikingly lower life satisfaction in the time before death. In fact, there is a clear pattern, according to which life satisfaction declines as a distance-to-death time variable comes closer to zero. In the investigation here, future death indicators up to five years in advance of a person's death are used. As these variables can only refer to events up to 2011, this fits in well with the above decision to only include waves up to 2006 in the data sample (Set 3) used in this third part of the analysis.

The main dependent variable in this paper is obtained at the end of each annual SOEP questionnaire, when interviewees have to assess their general life satisfaction on a scale ranging from 0 (“completely dissatisfied”) to 10 (“completely satisfied”). As this question (“How satisfied are you with your life, all things considered?”) is part of the questionnaire in every survey wave, the SOEP data set is very attractive for empirical research on the determinants of happiness and has therefore been used for this purpose numerous times over the last decades. ${ }^{12}$ Some years ago, the survey organizers added a question on respondents' happiness over the previous four weeks, which so far has received less attention among

\footnotetext{
${ }^{10}$ This is a conservative approach. Note that Watson and Wooden (forthcoming) reserve only one wave of data.

${ }^{11}$ There are more than 5,000 reported cases of dead former SOEP participants. Since 2000, the annual death rate is always above 100 and amounts to, in some years, more than 300 fatalities.

${ }^{12}$ See the survey "Well-Being and Happiness - A Compilation of SOEP Based Articles" on the SOEP webpage.
} 
researchers. ${ }^{13}$ To ensure clarity, the paper distinguishes between the latter as an affective measure of happiness and the main variable as the cognitive measure of happiness (i.e. overall life satisfaction).

Happiness research has revealed a large number of factors influencing individual well-being. These determinants can be used as control variables in multiple regression analyses, which is particularly important in order to isolate the willingness-to-participate factor in the interviewer contacts data. Thanks to detailed information on people's lives, it is possible to consider a variety of relevant factors while other survey aspects might also play a role. Specifically, the interview mode can directly influence satisfaction measurement (Conti and Pudney 2011) and possibly indirectly via selection effects caused by the above-mentioned design of the SOEP (Haisken-DeNew and Frick 2005). Recall that the primary interview mode is the oral interview between interviewer and respondent. If this is not possible, and especially when people reveal a tendency to refuse the interview completely, other modes are offered. As this may imply a basic group difference in respondent motivation, the survey mode variable could be considered as endogenously determined. Another relevant survey factor in the analysis of life satisfaction is the panel experience of interviewees, which also can affect responses directly (Chadi 2013a) and via correlations with variables of interest here. On average, fewer interviewer contacts are needed for more experienced respondents who spent more years in the panel (see Appendix Table A2), which would justify using such additional controls.

In regard to methodology, linear regressions are a generally accepted way to deal with the SOEP data and its satisfaction scores (Ferrer-i-Carbonell and Frijters 2004). To tackle potential concerns regarding the ordinal character of the dependent variable, ordered probit models can be implemented to check the results' robustness. Furthermore, due to the hierarchical data structure with individual, household and interviewer levels, the use of mixed linear models appears as an option (Hox 1994). ${ }^{14}$ Most importantly, the instrumental variable approach promises insights concerning the question of causality between respondent motivation and self-reported happiness. In order to approach causal estimates of the determinants of happiness, researchers typically apply fixed-effects estimators to control for unobserved but fixed individual heterogeneity. However, getting rid of the impact from given personality traits also implies getting rid of any fixed element in people's motivational

\footnotetext{
${ }^{13}$ With regards to happiness and three other feelings (anger, worry, sadness), interviewees are asked since 2007: "Please indicate for each feeling how often or rarely you experienced this feeling in the last four weeks."

${ }^{14}$ All additional analyses that are mentioned but not presented are available from the author upon request.
} 
attitude. The fixed-effects regression is therefore not considered as the superior method in this paper and is implemented only with reservation.

\section{Findings}

The number of interviewer contacts is the first variable from the SOEP paradata exploited in the following. While it provides evidence on the potential link between people's motivation to participate in a survey and their reported well-being, it also allows analyses in the vein of Heffetz and Rabin (2013) where contact information is interpreted directly as an indicator for people's reachability. While it is an interesting question whether their intriguing findings revealed in the SOC hold true for the German data, this first step also enhances the understanding of the interviewer contacts information. As Heffetz and Rabin illustrate their main findings graphically, the first output here is produced in a similar fashion.

Figure 1 shows averages of reported life satisfaction scores by number of interviewer contacts. The first important insight is that there is no general link between this indicator for the difficulty-of-reaching and happiness levels (also see Appendix Table A2), which is in line with Heffetz and Rabin. In contrast to their study, however, the distinction between men and women does not seem to reveal any significant disparity in connection with reachability (A). One could interpret this as good news for happiness researchers who are afraid of selection problems when studying gender differences with SOEP data. Regarding the next group differentiation between households with children and without, the picture for the happiness averages is generally in line with Heffetz and Rabin and suggests that reachability is related to the children-happiness gap (B). While children are a positive aspect in the lives of people, the harder the respondents are to reach, the less such a difference exists. However, additional regression analyses show that this trend is not robust to the consideration of control variables, indicating that the situation is not that severe compared to the SOC data. Essentially, this is true for all examined aspects, including age (C). The only graphical finding that is to some extent robust in multiple regression analyses comes from distinguishing between prime-aged people who are more and less successful in life, approximated via education and income levels (F). This gap appears to increase the harder it is to reach people. Although the results are not very strong, the interpretation is certainly intuitive. As is known from the analysis of people's income, the very rich can be difficult to convince to participate in surveys. The same might be true for people in very bad economic conditions. So, while the former might be very happy and the latter very unhappy, surveys might underestimate the gap in life satisfaction. The fact that the difference is still extremely large may explain why such an underestimation problem, if it exists, does not have the potential to trigger much attention or concern. 
Figure 1 Self-reported happiness by number of interviewer contacts

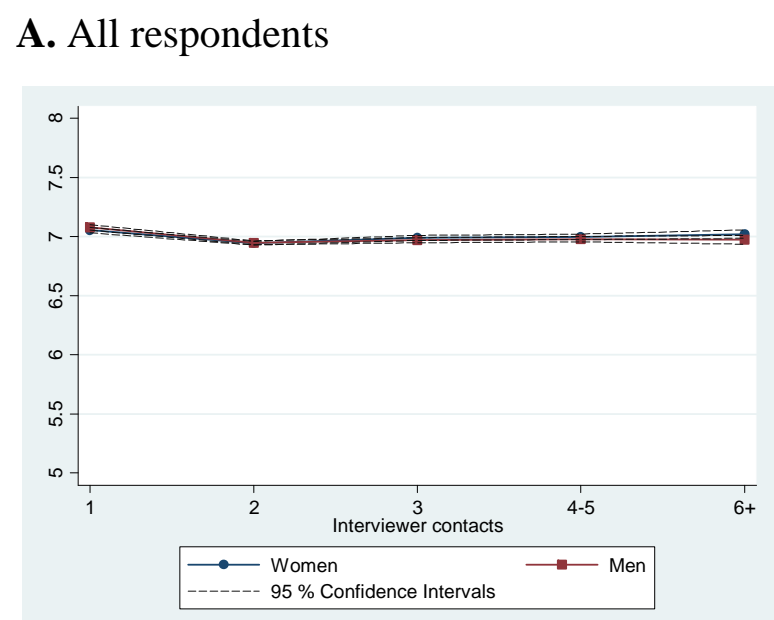

B. All respondents

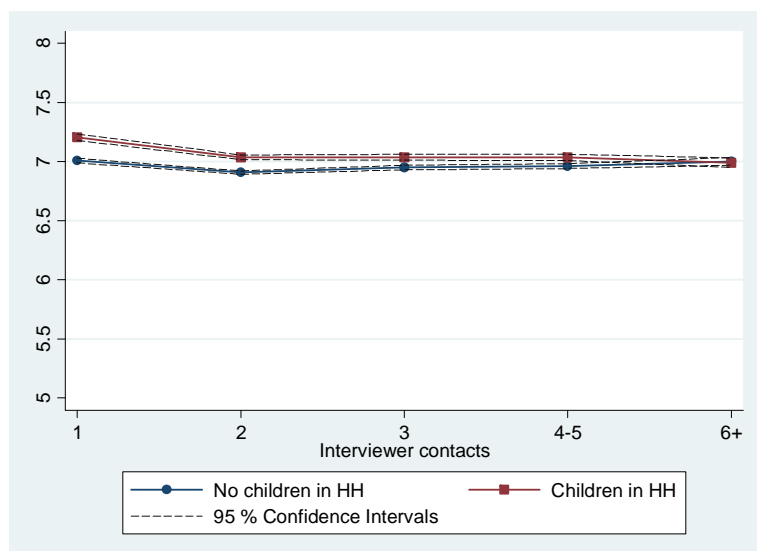

\section{All respondents}

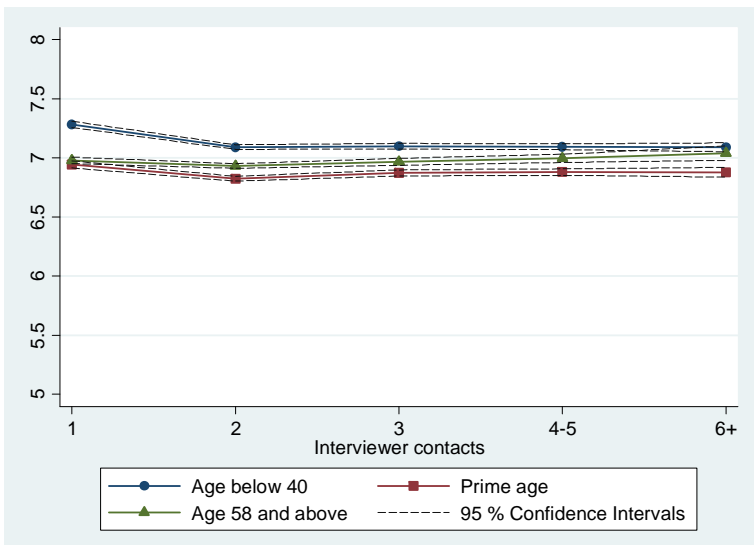

D. All respondents

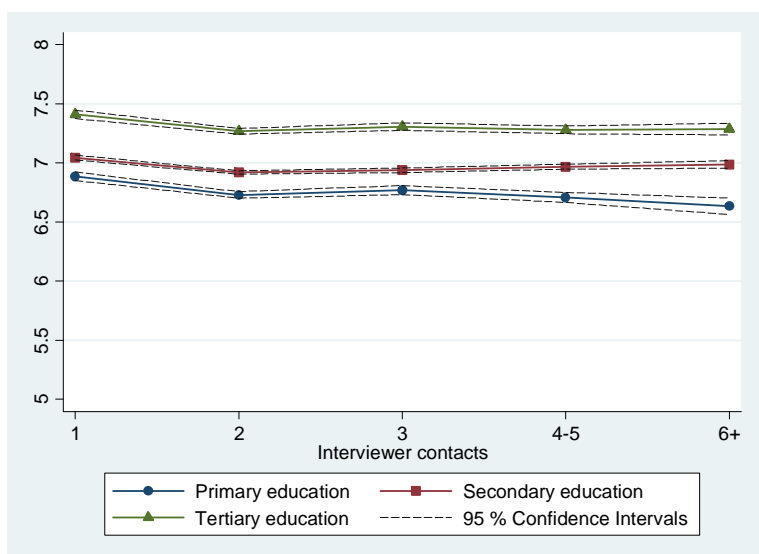

E. All respondents

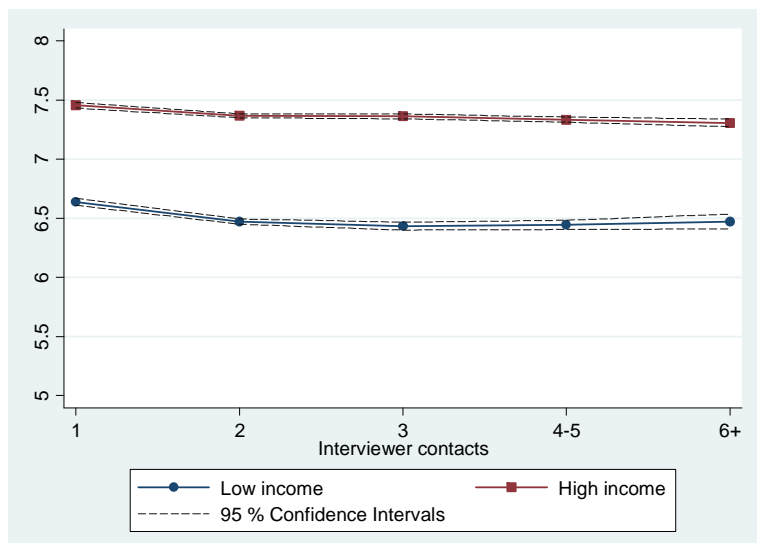

F. Only prime-aged respondents

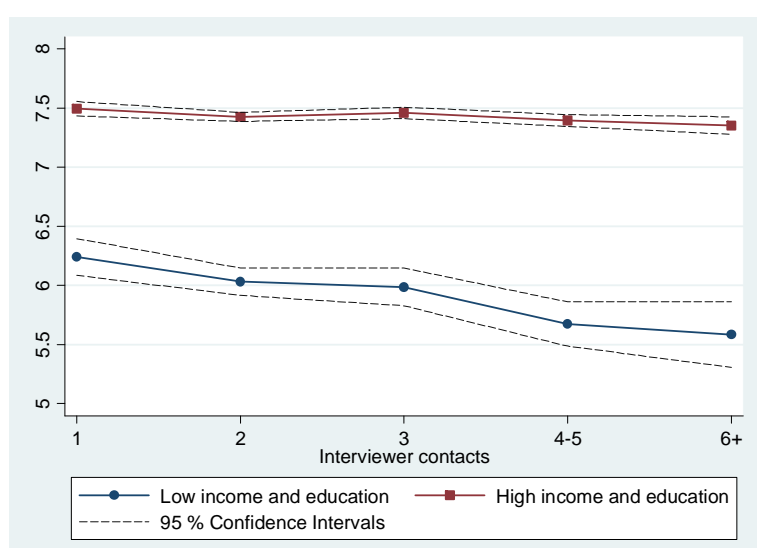

Note: The illustrations are based on SOEP data from 1995 to 2011 (Set 1, see Appendix Table A1). 
Table 1 Interviewer contacts and life satisfaction responses (standard regressions)

Specification:

(1)

(2)

(3)

(4)

(5)

(6)

Number of
interviewer contacts
Interviewer contacts:
one
Interviewer contacts:
two
Interviewer contacts:
three
Interviewer contacts:
four or five
Interviewer contacts:
six or more

$\begin{array}{ccccc}-0.003 & -0.015^{* * *} & -0.019^{* * *} & -0.028^{* * *} & -0.028^{* * *} \\ (0.002) & (0.002) & (0.002) & (0.002) & (0.002)\end{array}$

Reference

category

$-0.090 * * *$

$(0.009)$

$-0.102^{* * *}$

(0.011)

$-0.136^{* * *}$

$(0.011)$

$-0.197 * * *$

(0.014)

Employment status

Regular part-time

employment

Marginal, irregular

part-time

Other forms of

employment

Out of labor force

Reference category: full-time employment

$\begin{array}{ccccc}0.036^{* * *} & 0.055^{* * *} & 0.101^{* * *} & 0.051^{* * *} & 0.052^{* * *} \\ (0.011) & (0.011) & (0.011) & (0.012) & (0.012) \\ -0.137^{* * *} & -0.087^{* * *} & 0.046^{* *} & 0.063^{* * *} & 0.064^{* * *} \\ (0.019) & (0.019) & (0.018) & (0.018) & (0.018) \\ 0.059^{* * *} & 0.228^{* * *} & 0.323^{* * *} & 0.286^{* * *} & 0.287^{* * *} \\ (0.022) & (0.022) & (0.022) & (0.023) & (0.023) \\ -0.375^{* * *} & -0.309^{* * *} & -0.120^{* * *} & 0.101^{* * *} & 0.102^{* * *} \\ (0.008) & (0.008) & (0.008) & (0.010) & (0.010)\end{array}$

Education

Primary education

Reference category: secondary education

$$
\begin{array}{cccc}
-0.164 * * * & -0.070^{* * *} & -0.093^{* * *} & -0.094^{* * *} \\
(0.010) & (0.010) & (0.009) & (0.009) \\
0.307^{* * *} & 0.045^{* * *} & 0.115^{* * *} & 0.115^{* * *} \\
(0.009) & (0.009) & (0.009) & (0.009) \\
& & & \\
& 0.803^{* * *} & 0.543^{* * *} & 0.543^{* * *} \\
& (0.009) & (0.009) & (0.009)
\end{array}
$$

Log equalized real income

\begin{tabular}{lcccccc}
\hline Additional controls & No & No & No & No & Yes & Yes \\
Health controls & No & No & No & No & Yes & Yes \\
\hline $\mathrm{N}($ Set 1$)$ & 249,919 & 249,919 & 249,919 & 249,919 & 249,919 & 249,919 \\
adjusted $\mathrm{R}^{2}$ & 0.000 & 0.011 & 0.018 & 0.060 & 0.169 & 0.169 \\
\hline
\end{tabular}

Levels of statistical significance are: $* \mathrm{p}<0.1, * * \mathrm{p}<0.05, * * * \mathrm{p}<0.01$

Notes: Life satisfaction is the dependent variable. Number of interviewer contacts is a linear variable ranging from 1 to 9 . Additional controls are variables for unemployment, owner of dwelling, housing conditions, living area, household member in need of care, number of persons in household, no children in household, recent move, family status, partnership, age, gender, year and federal state. Health controls are variables for the degree of disability, doctor visits, and nights in hospital. Heteroscedasticity-robust standard errors are in parentheses.

One insight from this first inspection of the data is that the factors education and income play a role in the context of contact attempts which are needed by the interviewers to realize the interviews. These aspects appear in the following as control variables to identify respondent motivation as residual information in the number of interviewer contacts. Table 1 shows how 
the relationship between this variable and reported life satisfaction changes, as a result of considering more and more reasons for varying reachability. The first specification without any covariate shows again that, on average, there is no link between interviewer contacts and life satisfaction. However, the more the regression models control for the positive aspects of the lives that many hard-to-reach people lead, the more the relationship between contact number and happiness turns out to be negative. When interpreting the effects, it is important to consider the proxy role of factors like tertiary education. Many people with higher degrees from the education system have interesting but challenging jobs and are probably very busy, which is a driver of higher contact numbers. Meanwhile, determinants of bad reachability, like income, also have a very positive impact on individual well-being. As a result, the general link between interviewer contacts and reported happiness appears initially as too positive, and the negative factor of low respondent motivation is only revealed when other aspects are held constant.

As discussed in the previous section, the question of this finding's robustness relates to several issues. The hierarchical data structure may play a role, as dependencies across observations within the same household or interviewer cluster can occur, and standard errors are probably too low. So, while there is reason to consider empirical tools other than linear regressions with heteroscedasticity-robust standard errors, the negative link found appears to be robust to a whole variety of checks, whether these are carried out via clustering or hierarchical models. The large magnitude of the effect ensures that the methodological question does not matter much, as the gap of reported happiness between those who are contacted in the first attempt and the hardest-to-reach interviewees amounts to about 0.2 on the life satisfaction scale, when using the full set of control variables. Only if individual fixed effects are considered, the coefficient of the contacts variable becomes markedly smaller.

The application of fixed-effects regressions in Table 2 addresses the potential impact of fixed but unobserved personality traits on well-being outcomes and shows again a negative effect of higher interviewer contacts. This implies that, for one and the same person, requiring more contact attempts goes along with lower self-reported happiness. Recall that the consideration of fixed individual effects prohibits identification of the impact from constant unwillingness among people who are always hard to reach. As the role of the interviewer contacts might also interact with other survey aspects, Table 2 shows results for regression models that include variables for years in panel and interview mode. In fact, the coefficient becomes a little bit stronger when considering the former, which is in line with the expectation that the positivity bias in the first years of participation is falsely reflected in the higher number of interviewer 
Table 2 Interviewer contacts and life satisfaction responses

\begin{tabular}{lcccccc}
\multicolumn{1}{r}{ Method: } & \multicolumn{3}{c}{ Standard regressions } & \multicolumn{3}{c}{ Fixed effects regressions } \\
\multicolumn{1}{c}{ Specification: } & $(1)$ & $(2)$ & $(3)$ & $(1)$ & $(2)$ & $(3)$ \\
\hline \multirow{2}{*}{$\begin{array}{l}\text { Number of } \\
\text { interviewer contacts }\end{array}$} & $-0.028^{* * *}$ & $-0.037^{* * *}$ & $-0.026^{* * *}$ & $-0.012^{* * *}$ & $-0.014^{* * *}$ & $-0.010^{* * *}$ \\
& $(0.002)$ & $(0.002)$ & $(0.002)$ & $(0.002)$ & $(0.002)$ & $(0.002)$ \\
& & & & & & Yes \\
\hline Standard controls & Yes & Yes & Yes & Yes & Yes \\
Health controls & Yes & Yes & Yes & Yes & Yes & Yes \\
Year in panel & No & Yes & Yes & No & Yes & Yes \\
Interview mode & No & No & Yes & No & No & Yes \\
\hline N (Set 1) & 249,919 & 249,919 & 249,919 & 249,919 & 249,919 & 249,919 \\
adjusted $\mathrm{R}^{2}$ & 0.169 & 0.176 & 0.184 & 0.055 & 0.057 & 0.061 \\
\hline
\end{tabular}

Levels of statistical significance: $* \mathrm{p}<0.1, * * \mathrm{p}<0.05$, $* * * \mathrm{p}<0.01$

Notes: Life satisfaction is the dependent variable. Number of interviewer contacts is a linear variable ranging from 1 to 9. Standard controls include variables for employment status, unemployment, education, income, owner of dwelling, housing conditions, living area, household member in need of care, number of persons in household, no children in household, recent move, family status, partnership, age, gender (used only in the standard regressions), year and federal state. Health controls are variables for the degree of disability, doctor visits, and nights in hospital. Year in panel variables include dummies for the first survey participations. Interview mode variables are in line with the categories in Appendix Table A1. Heteroscedasticity-robust standard errors are in parentheses.

contacts that respondents require at first. Regarding the role of the interview mode, it seems that without controls for it the positivity bias associated with oral interviews is falsely reflected in smaller contact numbers. Due to the above-mentioned selection effects, however, the interview mode may also capture some of the lower willingness of participants and the corresponding attitudinal effect, so its role is not clear-cut. Most importantly, the main finding cannot be rejected in any of these additional regressions, so the analysis continues with the second measure for respondent motivation after summarizing that multiple regression analyses do indeed confirm a negative link between happiness responses and number of interviewer contacts as an indicator of low respondent motivation.

Table 3 presents two major findings. First, the willingness to participate in the interview is related even more strongly to self-reported happiness when the more direct measure from the interviewer data is used. Accordingly, a very good motivation is linked to higher life satisfaction, compared to other categories, even if a large set of influencing factors is considered as controls and fixed-effects regressions are applied. Note that this result does not depend on the use of the control variables, as it appears also in the average values (see Appendix Table A3). Also note that the number of interviewer contacts is clearly related to the level of willingness, so that less willingness goes along with worse reachability. Having said this, the second finding is that the negative link between interviewer contacts and life 
Table 3 Interviewee's willingness to participate and life satisfaction responses

\begin{tabular}{|c|c|c|c|c|c|c|}
\hline \multirow{2}{*}{$\begin{array}{r}\text { Method: } \\
\text { Specification: }\end{array}$} & \multicolumn{3}{|c|}{ Standard regressions } & \multicolumn{3}{|c|}{ Fixed effects regressions } \\
\hline & $(1)$ & (2) & (3) & (1) & $(2)$ & (3) \\
\hline $\begin{array}{l}\text { Number of } \\
\text { interviewer contacts }\end{array}$ & $\begin{array}{c}-0.031^{* * *} \\
(0.004)\end{array}$ & $\begin{array}{c}-0.017 * * * \\
(0.004)\end{array}$ & $\begin{array}{c}-0.012 * * * \\
(0.004)\end{array}$ & $\begin{array}{c}-0.012 * * * \\
(0.004)\end{array}$ & $\begin{array}{l}-0.008^{*} \\
(0.004)\end{array}$ & $\begin{array}{l}-0.005 \\
(0.004)\end{array}$ \\
\hline $\begin{array}{l}\text { Willingness to } \\
\text { participate }\end{array}$ & \multicolumn{3}{|c|}{$\begin{array}{c}\text { Reference category: } \\
\text { very good }\end{array}$} & & \multicolumn{2}{|c|}{$\begin{array}{c}\text { Reference category: } \\
\text { very good }\end{array}$} \\
\hline Good & & $\begin{array}{c}-0.281 * * * \\
(0.015)\end{array}$ & $\begin{array}{c}-0.254^{* * *} \\
(0.015)\end{array}$ & & $\begin{array}{c}-0.126 * * * \\
(0.018)\end{array}$ & $\begin{array}{c}-0.118 * * * \\
(0.018)\end{array}$ \\
\hline Bad & & $\begin{array}{c}-0.544 * * * \\
(0.037)\end{array}$ & $\begin{array}{c}-0.517 * * * \\
(0.037)\end{array}$ & & $\begin{array}{c}-0.277 * * * \\
(0.039)\end{array}$ & $\begin{array}{c}-0.263 * * * \\
(0.039)\end{array}$ \\
\hline Very bad & & $\begin{array}{c}-0.710^{* * *} \\
(0.077)\end{array}$ & $\begin{array}{c}-0.651^{* * * *} \\
(0.078)\end{array}$ & & $\begin{array}{c}-0.334^{* * *} \\
(0.089)\end{array}$ & $\begin{array}{c}-0.315 * * * \\
(0.090)\end{array}$ \\
\hline Standard controls & Yes & Yes & Yes & Yes & Yes & Yes \\
\hline Health controls & Yes & Yes & Yes & Yes & Yes & Yes \\
\hline Survey factors & No & No & Yes & No & No & Yes \\
\hline $\begin{array}{l}\mathrm{N}(\text { Set } 2) \\
\text { adjusted } \mathrm{R}^{2}\end{array}$ & $\begin{array}{c}76,236 \\
0.186\end{array}$ & $\begin{array}{c}76,236 \\
0.193\end{array}$ & $\begin{array}{c}76,236 \\
0.207\end{array}$ & $\begin{array}{c}76,236 \\
0.040\end{array}$ & $\begin{array}{c}76,236 \\
0.042\end{array}$ & $\begin{array}{c}76,236 \\
0.046\end{array}$ \\
\hline
\end{tabular}

Levels of statistical significance: $* \mathrm{p}<0.1,{ }^{* *} \mathrm{p}<0.05$, *** $\mathrm{p}<0.01$

Notes: See Table 2. Survey factors include the year in panel and the interview mode variables.

satisfaction responses in the regression models becomes weaker when the more direct measure for respondent motivation is used in the model. This supports the interpretation of the isolated negative effect of interviewer contacts as an indicator of low motivation among those who are harder to reach.

For good reason, the exploitation of interviewer judgments about respondent motivation might be considered as problematic. Firstly, there is a clear link between the probability of an oral interview and the willingness indicator, so that the latter might be a proxy for the positivity bias associated with a face-to-face situation. Hence, Table 3 also shows results for models that include interview factors, but the effects linked to respondent motivation remain large and significant. Secondly, it is possible that interviewers tend to portray the result of their work as too positive. Because it is their job to motivate respondents to give qualitative answers, not all cases of low willingness might be captured by such a variable. In fact, its distribution is heavily skewed (see Appendix Table A3). Note that people with no motivation to do the interview may simply refuse, whereas the quality of data from those interviews that still took place is clearly worse among the less willing. ${ }^{15}$ Considering these problems, one may argue that it is even more impressive to obtain such strong evidence on the link between respondent motivation and self-reported happiness.

\footnotetext{
${ }^{15}$ Table A3 provides evidence for this, as lower willingness goes along with a larger loss of observation numbers (due to missing values) when comparing the final sample (Set 2) to the entire available data from that period.
} 
A. Averages in life satisfaction

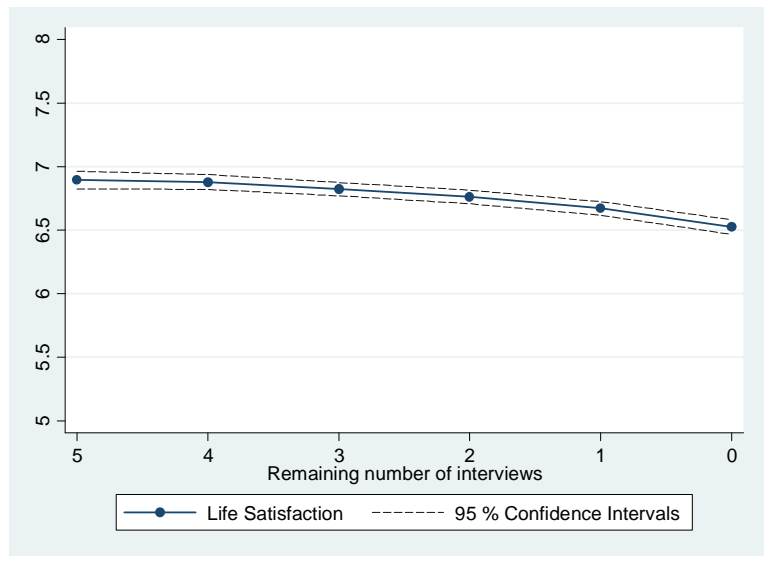

C. Averages in health satisfaction

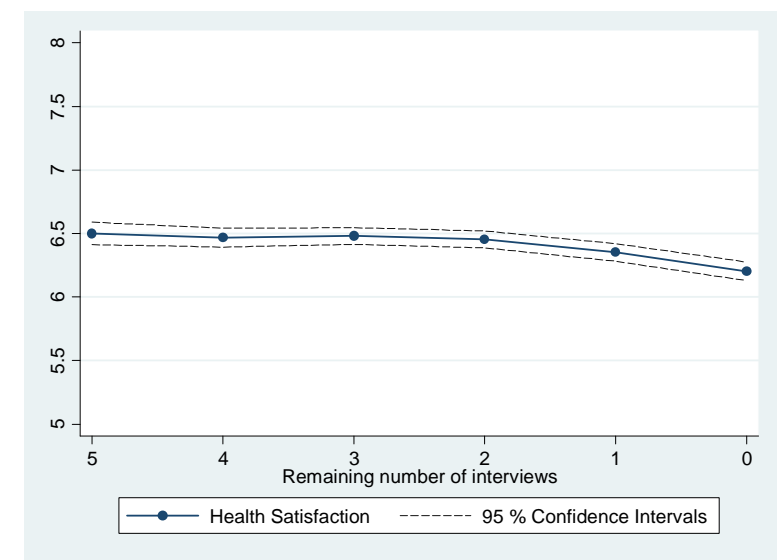

B. Share of motivated participants

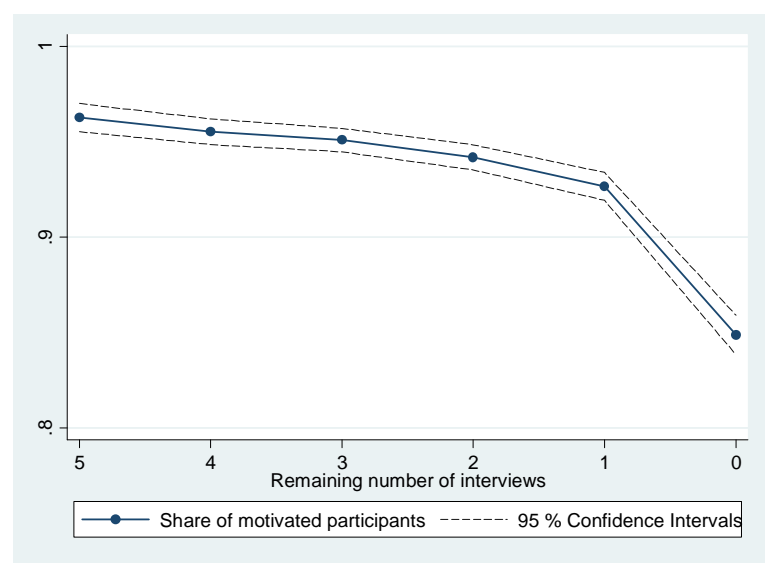

D. Share of people without bad health

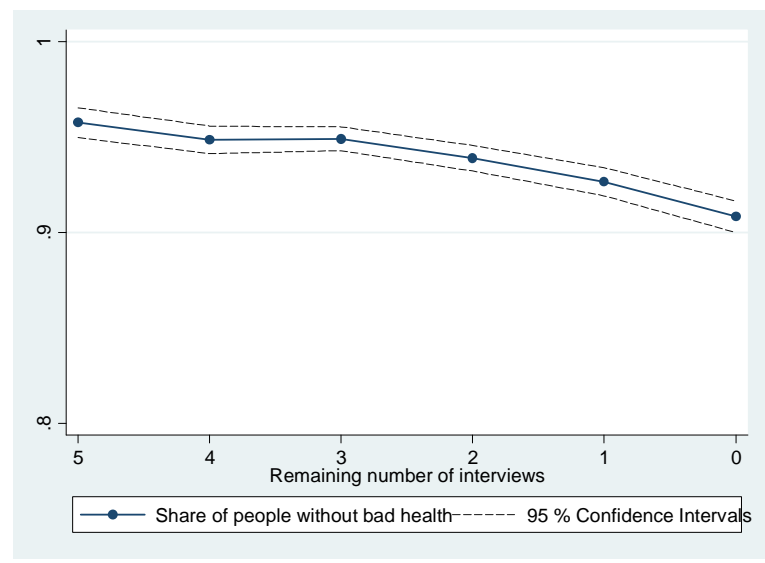

Notes: The illustrations are based on SOEP data from 1995 to 2006 (Set 3, see Appendix Table A1). Life and health satisfaction are both measured on a scale ranging from 0 ("completely dissatisfied") to 10 ("completely satisfied"). Motivated participants are those who are considered as having either "good" or "very good" willingness to participate in the survey, according to interviewers' judgments. Bad health is a binary variable that is derived from a subjective health variable with five categories.

The evidence presented so far is at odds with the assumption that potential non-respondents do not differ in regard to their well-being from those who are motivated to continue participating in a survey. Hence, the rest of the empirical analysis exploits the panel structure of the data to identify and analyze future non-respondents while they are still participating. Recall that the main reason for non-response is refusal, which obviously reflects the strongest and most objective testimony of unwillingness to do an interview. Therefore, it is plausible to expect that those who are about to leave the panel do not behave in the same way as those who continue willingly. The identification of SOEP participants who actually have left the panel allows utilization of this information to generate another indicator of potentially lower respondent motivation. 
Table 4 Leaving the panel and life satisfaction responses

\begin{tabular}{lllllll}
\hline A. & \multicolumn{3}{c}{\begin{tabular}{c} 
Method: \\
\multicolumn{1}{c}{ Specification: }
\end{tabular}} & \multicolumn{1}{c}{ Standard regressions } & \multicolumn{3}{c}{ Fixed effects regressions } \\
& & $(2)$ & $(3)$ & \multicolumn{1}{c}{$(1)$} & $(2)$ & $(3)$ \\
\hline \multirow{3}{*}{ Last participation } & $-0.236^{* * *}$ & $-0.291^{* * *}$ & $-0.257^{* * *}$ & $-0.334^{* * *}$ & $-0.308^{* * *}$ & $-0.286^{* * *}$ \\
& $(0.017)$ & $(0.017)$ & $(0.017)$ & $(0.024)$ & $(0.024)$ & $(0.024)$ \\
2nd last participation & $-0.200^{* * *}$ & $-0.226^{* * *}$ & $-0.204^{* * *}$ & $-0.230^{* * *}$ & $-0.213^{* * *}$ & $-0.201^{* * *}$ \\
& $(0.018)$ & $(0.018)$ & $(0.017)$ & $(0.021)$ & $(0.021)$ & $(0.021)$ \\
3rd last participation & $-0.148^{* * *}$ & $-0.163^{* * *}$ & $-0.143^{* * *}$ & $-0.121^{* * *}$ & $-0.111^{* * *}$ & $-0.102^{* * *}$ \\
& $(0.018)$ & $(0.018)$ & $(0.018)$ & $(0.019)$ & $(0.019)$ & $(0.019)$ \\
4th last participation & $-0.106^{* * *}$ & $-0.120^{* * *}$ & $-0.101^{* * *}$ & $-0.053^{* * *}$ & $-0.050^{* * *}$ & $-0.042^{* *}$ \\
& $(0.019)$ & $(0.018)$ & $(0.018)$ & $(0.017)$ & $(0.017)$ & $(0.017)$ \\
& & & & & & \\
\hline Standard controls & Yes & Yes & Yes & Yes & Yes & Yes \\
Survey factors & No & Yes & Yes & No & Yes & Yes \\
Health controls & No & No & Yes & No & No & Yes \\
\hline N (Set 3) & 176,519 & 176,519 & 176,519 & 176,519 & 176,519 & 176,519 \\
adjusted R ${ }^{2}$ & 0.141 & 0.157 & 0.187 & 0.048 & 0.053 & 0.062 \\
\hline
\end{tabular}

B.

Method: $\quad$ Standard regressions Specification: (4)

(5)

(6)

Fixed effects regressions

\begin{tabular}{|c|c|c|c|c|c|c|}
\hline Specification: & (4) & (5) & (6) & (4) & (5) & (6) \\
\hline Last participation & $\begin{array}{c}-0.197 * * * \\
(0.017)\end{array}$ & $\begin{array}{c}-0.152^{* * *} \\
(0.016)\end{array}$ & $\begin{array}{c}-0.137 * * * \\
(0.016)\end{array}$ & $\begin{array}{c}-0.182 * * * \\
(0.025)\end{array}$ & $\begin{array}{c}-0.162^{* * * *} \\
(0.024)\end{array}$ & $\begin{array}{c}-0.148 * * * \\
(0.023)\end{array}$ \\
\hline $\begin{array}{l}\text { 2nd last } \\
\text { participation }\end{array}$ & $\begin{array}{c}-0.174^{* * *} \\
(0.018)\end{array}$ & $\begin{array}{c}-0.138 * * * \\
(0.017)\end{array}$ & $\begin{array}{c}-0.127^{* * * *} \\
(0.016)\end{array}$ & $\begin{array}{c}-0.150 * * * \\
(0.022)\end{array}$ & $\begin{array}{c}-0.136^{* * * *} \\
(0.021)\end{array}$ & $\begin{array}{c}-0.128 * * * \\
(0.020)\end{array}$ \\
\hline $\begin{array}{l}\text { 3rd last } \\
\text { participation }\end{array}$ & $\begin{array}{c}-0.115^{* * *} \\
(0.018)\end{array}$ & $\begin{array}{c}-0.093^{* * * *} \\
(0.017)\end{array}$ & $\begin{array}{c}-0.089 * * * \\
(0.017)\end{array}$ & $\begin{array}{c}-0.060 * * * \\
(0.020)\end{array}$ & $\begin{array}{c}-0.055^{* * * *} \\
(0.019)\end{array}$ & $\begin{array}{c}-0.053^{* * * *} \\
(0.019)\end{array}$ \\
\hline $\begin{array}{l}\text { 4th last } \\
\text { Participation }\end{array}$ & $\begin{array}{c}-0.075^{* * *} \\
(0.019)\end{array}$ & $\begin{array}{c}-0.057 * * * \\
(0.018)\end{array}$ & $\begin{array}{c}-0.049 * * * \\
(0.017)\end{array}$ & $\begin{array}{l}-0.007 \\
(0.017)\end{array}$ & $\begin{array}{l}-0.009 \\
(0.017)\end{array}$ & $\begin{array}{l}-0.007 \\
(0.017)\end{array}$ \\
\hline $\begin{array}{l}\text { Death in about one } \\
\text { year }\end{array}$ & $\begin{array}{c}-0.508 * * * \\
(0.061)\end{array}$ & $\begin{array}{c}-0.153^{* * * *} \\
(0.054)\end{array}$ & $\begin{array}{l}-0.088^{*} \\
(0.053)\end{array}$ & $\begin{array}{c}-0.713^{* * *} \\
(0.070)\end{array}$ & $\begin{array}{c}-0.461 * * * \\
(0.065)\end{array}$ & $\begin{array}{c}-0.417 * * * \\
(0.063)\end{array}$ \\
\hline $\begin{array}{l}\text { Death in about two } \\
\text { years }\end{array}$ & $\begin{array}{c}-0.223 * * * \\
(0.056)\end{array}$ & $\begin{array}{c}0.060 \\
(0.050)\end{array}$ & $\begin{array}{l}0.107 * * \\
(0.048)\end{array}$ & $\begin{array}{c}-0.331 * * * \\
(0.060)\end{array}$ & $\begin{array}{c}-0.172 * * * \\
(0.057)\end{array}$ & $\begin{array}{c}-0.147^{* * * *} \\
(0.055)\end{array}$ \\
\hline $\begin{array}{l}\text { Death in about three } \\
\text { years }\end{array}$ & $\begin{array}{c}-0.205^{* * *} \\
(0.054)\end{array}$ & $\begin{array}{c}0.055 \\
(0.048)\end{array}$ & $\begin{array}{l}0.090 * * \\
(0.046)\end{array}$ & $\begin{array}{c}-0.302 * * * \\
(0.054)\end{array}$ & $\begin{array}{c}-0.175^{* * * *} \\
(0.051)\end{array}$ & $\begin{array}{c}-0.156^{* * * *} \\
(0.050)\end{array}$ \\
\hline $\begin{array}{l}\text { Death in about four } \\
\text { years }\end{array}$ & $\begin{array}{c}-0.201 * * * \\
(0.052)\end{array}$ & $\begin{array}{l}-0.004 \\
(0.047)\end{array}$ & $\begin{array}{c}0.027 \\
(0.046)\end{array}$ & $\begin{array}{c}-0.280 * * * \\
(0.051)\end{array}$ & $\begin{array}{c}-0.194 * * * \\
(0.048)\end{array}$ & $\begin{array}{c}-0.180 * * * \\
(0.047)\end{array}$ \\
\hline $\begin{array}{l}\text { Death in about five } \\
\text { years }\end{array}$ & $\begin{array}{c}-0.188^{* * *} \\
(0.048)\end{array}$ & $\begin{array}{c}0.017 \\
(0.044)\end{array}$ & $\begin{array}{c}0.054 \\
(0.041)\end{array}$ & $\begin{array}{c}-0.175^{* * *} \\
(0.043)\end{array}$ & $\begin{array}{c}-0.107 * * * \\
(0.041)\end{array}$ & $\begin{array}{c}-0.092 * * \\
(0.041)\end{array}$ \\
\hline Standard controls & Yes & Yes & Yes & Yes & Yes & Yes \\
\hline Survey factors & Yes & Yes & Yes & Yes & Yes & Yes \\
\hline Health controls & Yes & Yes & Yes & Yes & Yes & Yes \\
\hline Subjective health & No & Yes & Yes & No & Yes & Yes \\
\hline Health satisfaction & No & No & Yes & No & No & Yes \\
\hline $\mathrm{N}($ Set 3) & 176,519 & 176,519 & 176,519 & 176,519 & 176,519 & 176,519 \\
\hline adjusted $\mathrm{R}^{2}$ & 0.188 & 0.290 & 0.344 & 0.064 & 0.110 & 0.137 \\
\hline
\end{tabular}

Levels of statistical significance: $* \mathrm{p}<0.1,{ }^{* *} \mathrm{p}<0.05, * * * \mathrm{p}<0.01$

Notes: See Table 2. Survey factors include the year in panel and the interview mode variables. 
In line with these considerations, the first graphical illustration (A) in Figure 2 demonstrates a clear relationship between life satisfaction and future non-response. There is a decline in reported happiness, which becomes more and more obvious as time left in the panel heads towards zero. At the same time, there is a strong decline in people's willingness to participate (B). This underlines the idea to use future non-response as an indicator of low respondent motivation. Besides, the aspect of health seems relevant in this context, as it declines similarly (C, D) and thus needs to be considered analysis. Recall that being ill and leaving the panel because of that can reflect true unhappiness as a determinant of survey refusal, while reporting negatively only due to aversion towards the interview is a measurement error.

As can be seen in the regression output of Table 4, the main insight from the graphical analysis is robust to consideration of a broad set of control variables, including survey factors, and also to the issue of fixed individual effects. To closer inspect this strong link between willingness of participating and life satisfaction responses, the aspect of health is considered in multiple ways. This also concerns variables on subjective health, which researchers of happiness are typically averse to using. While such controls might actually capture some of the impact of the variable of interest and thus might lead to underestimated effects, the results are even then remarkably robust. Concretely, the models include variables for subjective health measured in five categories (from very good to very bad) and health satisfaction (measured on a 0 to 10 scale), in addition to the objective health variables. Panel B regressions also include the time-to-death variables, which indicate significant distress at the end of people's lives. Although the negative effects related to future non-response seem to become somewhat smaller the more aspects are held constant, still, the last years in the panel are linked throughout the analysis to significantly lower life satisfaction responses. ${ }^{16}$

The final part of the analysis exploits another form of technical information to specifically address the question of causality. The strong and robust results suggest a causal effect of respondent motivation on self-reported happiness; yet, the potential endogeneity in this relationship is hard to dispose of without some form of randomization. To this aim, the last interviews of panel dropouts are looked at more carefully. While in some cases panel attrition is possibly related to true individual unhappiness and unobserved reasons for it, in other cases it is indeed, and only, the low motivation of people that leads to the refusal. To identify such a random group of future non-respondents which is not selected based on aspects related to

\footnotetext{
${ }^{16}$ According to the argument of Section 3, those respondents who actually re-enter the panel show a weaker form of unwillingness. Indeed, additional analyses show negative effects for these persons with lower motivation but the effects are not similarly strong and robust as in case of the permanent panel leavers. Since these results do not offer new insights, regression results are not reported here but are available from the author upon request.
} 
well-being, the following instrumental variable regression exploits the event of interviewer attrition, which happens e.g. when interviewers quit their job. Well-known among survey organizers, interviewer dropouts can increase the probability that unmotivated interviewees use this opportunity to exit the panel as well. Comprehensive investigations into the determinants of panel attrition confirm the effect of interviewer (dis)continuity on response rates (e.g. Zabel 1998, Behr et al. 2005). Because in some studies this effect has been found to be "relatively small” (Watson and Wooden 2009) or even insignificant (Nicoletti and Peracchi 2005), the data set is expanded to the earlier waves of the SOEP data in order to ensure having a strong instrument. ${ }^{17}$ Another reason for this enlargement relates to a significant loss of data because the interview mode of self-written questionnaire without interviewer presence has to be dropped from this final part of the analysis. Logically, interviewer exit is not a meaningful trigger for interviewee dropout when there has been no personal contact. Moreover, the data set is further limited in line with the argument underlying the instrument, starting with the largest possible sample (Set 4, see Appendix Table A1).

It is important to note that being asked for an interview by a different person than before is not only irrelevant to people's well-being in the year before, it also specifically affects those individuals who are already reluctant and have a negative cooperation attitude. This apparently minor occurrence does not matter to people who are motivated to continue in the survey, but it does work for the unwilling as a "last straw" to finally provoke the decision to refuse participation. This consequence is the fear of survey organizers, which explains why interviewer continuity is one of the prime concerns to fight interviewee dropout. ${ }^{18}$

Table 5 shows the results from using interviewer dropouts in the subsequent survey year as an instrument for the last participation of an interviewee before exiting the panel. Using this randomized identification of individuals with low motivation to continue participating, the finding is a significantly negative effect on reported well-being when being interviewed for the last time. As interviewers usually deal with dozens of households per year, the interviewer dropout is exogenously given from the perspective of the respondent. Yet, in a hypothetical case, the interviewer's decision to quit might somehow be affected by an interviewee. ${ }^{19}$ To

\footnotetext{
${ }^{17}$ This goes along with a small change in the set of additional control variables. Recall that the objective health variables are not consistently available and thus have to be left out here. However, even if health satisfaction (which is consistently available) is added as a control variable to check the role of this aspect, it does not alter the finding. All other controls used in the analysis are available since 1985, which is the first wave that includes interviewer identification numbers. Testing for weakness of the instrument indicates that the empirical strategy is successful, as the F statistics extend any proposed critical value (see Table A4).

${ }^{18}$ As an interesting side effect of this policy, the SOEP, as one of the longest running panels in the world, has by now a group of interviewers with an average age far beyond 60 in the most recent waves.

${ }^{19}$ As a potential scenario, Wooden and Watson (2007) mention the case that a HILDA survey participant "had behaved in a threatening manner towards an interviewer.”
} 
Table 5 Leaving the panel and life satisfaction responses (instrumental variable regressions)

A. (no additional data restriction)

Method:

Two-stage least squares

\begin{tabular}{lccccc} 
Annual interviews per interviewer: & min. 1 & min. 2 & $\min .3$ & $\min .4$ & $\min .5$ \\
\hline & & & & & \\
Last participation of the respondent & $-0.357^{* *}$ & $-0.352^{* *}$ & $-0.378^{* *}$ & $-0.391^{* *}$ & $-0.388^{* *}$ \\
& $(0.176)$ & $(0.175)$ & $(0.178)$ & $(0.180)$ & $(0.181)$ \\
& Yes & Yes & Yes & Yes & Yes \\
& Yes & Yes & Yes & Yes & Yes \\
\hline Standard controls & 205,034 & 204,433 & 203,838 & 203,299 & 202,432 \\
Survey factors & 0.159 & 0.159 & 0.159 & 0.159 & 0.159 \\
\hline $\mathrm{N}($ Set 4) & & & & & \\
adjusted $\mathrm{R}^{2}$ &
\end{tabular}

B. overall participation years of each respondent: $\min .3$

Method:

Two-stage least squares

\begin{tabular}{lccccc} 
Annual interviews per interviewer: & $\min .1$ & $\min .2$ & $\min .3$ & $\min .4$ & $\min .5$ \\
\hline & & & & & \\
Last participation of the respondent & $-0.499^{* *}$ & $-0.496^{* *}$ & $-0.516^{* *}$ & $-0.532^{* *}$ & $-0.510^{* *}$ \\
& $(0.216)$ & $(0.216)$ & $(0.219)$ & $(0.220)$ & $(0.219)$ \\
& Yes & Yes & Yes & Yes & Yes \\
& Yes & Yes & Yes & Yes & Yes \\
\hline Standard controls & 197,680 & 197,101 & 196,554 & 196,063 & 195,253 \\
Survey factors & 0.160 & 0.160 & 0.160 & 0.160 & 0.160 \\
\hline adjusted $4 \mathrm{R}^{2}$ & & & & & \\
\hline
\end{tabular}

C. overall participation years of each respondent: $\min .5$

Method:

Two-stage least squares

\begin{tabular}{lccccc} 
Annual interviews per interviewer: & min. 1 & $\min .2$ & $\min .3$ & $\min .4$ & $\min .5$ \\
\hline & & & & & \\
Last participation of the respondent & $-0.622^{* *}$ & $-0.619^{* *}$ & $-0.649^{* * *}$ & $-0.654^{* * *}$ & $-0.624^{* *}$ \\
& $(0.247)$ & $(0.245)$ & $(0.247)$ & $(0.248)$ & $(0.247)$ \\
& & & & & \\
\hline Standard controls & Yes & Yes & Yes & Yes & Yes \\
Survey factors & Yes & Yes & Yes & Yes & Yes \\
\hline $\mathrm{N}($ Set 4) & 189,856 & 189,307 & 188,801 & 188,351 & 187,590 \\
adjusted $\mathrm{R}^{2}$ & 0.160 & 0.160 & 0.160 & 0.160 & 0.160 \\
\hline
\end{tabular}

Levels of statistical significance: $* \mathrm{p}<0.1,{ }^{* *} \mathrm{p}<0.05,{ }^{* * *} \mathrm{p}<0.01$

Notes: See Table 2. Survey factors include the year in panel and the interview mode variables. The instrument for a respondent's last year in the panel is the last year of the interviewer in the panel. Corresponding first stage results for Panel C are presented in Appendix Table A4.

tackle such concerns, the regressions in the second column of Table 5 use data which is limited to interviewers with at least two interviews per year. Despite an increasing loss of observations, the finding holds when this minimum requirement is raised even further in the subsequent columns.

The idea behind a second data restriction relates to the argument that interviewer exits may not matter much to interviewees in their first interviews who have not yet become familiar with the person asking for an interview (see Olsen 2005, Watson and Wooden 2009). This 
suggests using a sample that requires people to have participated in the panel for a certain period of time. Panel B in Table 5 presents results when one- and two-time participants are dropped. Panel $\mathrm{C}$ even requires a minimum of five participations. The result is a substantial increase in the magnitude of the measured effect, which appears to be even stronger than indicated in the panel regressions above. ${ }^{20}$ These results all confirm the existence of a causal impact from respondent motivation on self-reported happiness, as a randomly selected group of future non-respondents with low motivation to continue participating reports strongly reduced life satisfaction before leaving the panel. Recall that causality here means that reported happiness is biased downwards due to a measurement bias, as people's dissatisfaction with being interviewed does not reflect actual unhappiness. This requires a comprehensive discussion in the following and final section.

\section{Conclusion and Discussion}

To investigate people's response behavior and its role in the measurement of well-being, this study exploits information on the number of contacts required by each interviewer to arrange household interviews. The primary idea is to reveal differences in respondent motivation, anticipating that these are one reason why some people are harder to reach than others. Similar to Heffetz and Rabin (2013), the contact information can also be used to test whether empirical outcomes in happiness research depend on the people's reachability and thus on survey policies. All in all, the results for the German SOEP data appear less intriguing as they are in the American SOC, which particularly concerns the potential happiness gap between men and women. A first objection to this is that the question wording differs across surveys. ${ }^{21}$ Other objections may relate to the social or cultural differences between the people interviewed, but also to the survey design of the SOEP, which in contrast to the SOC with its many call attempts may frustrate dramatic results. In fact, many harder-to-reach and possibly less motivated people do not end up in the highest interviewer contact category in the SOEP, but they are given the opportunity to fill out questionnaires on their own and to submit those via mail. ${ }^{22}$ So, the Heffetz and Rabin argument, according to which differences in reachability

\footnotetext{
${ }^{20}$ Additional checks of the instrument also strengthen confidence in its validity. The effect of subsequent interviewer dropouts on self-reported happiness is insignificant as soon as subsequent interviewee dropout is included in the model. The effect is also insignificant when the data is restricted to those who stay in the panel. This suggests that there are no separate effects of future interviewer dropout on respondents and their well-being. ${ }^{21}$ Having a cognitive and an affective measure available in the SOEP, it is possible to conduct the same analyses again with the short-term happiness question that is certainly more similar to the one from the SOC. Yet, again there is no increase in happy men by number of contacts.

${ }^{22}$ Average life satisfaction in this group is known to be particularly low (Chadi 2013a). Yet, due to missing data on interviewer contacts, these observations are not part of the analysis here, as mentioned above.
} 
are capable of affecting happiness research findings, cannot be rejected based on the results here; but overall the problem seems less severe in this large and widely used panel data set.

After addressing this recent development in the research on survey factors and well-being measurement, the information on interviewer contacts is used as an indicator of people's motivation to do the interview. To achieve that, it is necessary to control for determinants of why some people are harder to reach. While there is no general relation between contact effort and averages in self-reported happiness, the negative effect of higher interviewer contacts is revealed in regression models when important control variables are included. The SOEP with its large set of technical survey information offers a very useful opportunity to investigate this finding further and to substantiate that respondent motivation matters. In fact, when applying a more direct measure of willingness to participate from interviewer evaluation data, the negative effect of interviewer contacts loses significance, suggesting that both variables measure differences in respondent motivation. Further evidence for an unwillingnessunhappiness relationship comes from the investigation of future panel quitters, showing that, prior to leaving the panel, self-reported happiness declines year by year until the final interview. The argument here is that actual non-response provides another indicator of unwillingness to do interviews, especially because most of the non-response is due to refusal. As these three indicators, along with their imperfections, cannot identify all of the truly unmotivated people, the consistent results are all the more remarkable, which leads to the question of causality.

The paper's expectation, formulated in advance of the empirical analysis, is that people's motivation to do surveys is linked to actual life satisfaction responses in a positive way which, vice versa, implies that less willing people respond more negatively when they report on their happiness. The first of the two reasons for such expectation relates to selectivity, according to which the unhappy are more likely to leave a panel, and that lower outcomes simply reflect their true state of well-being. Although the literature is far from being consistent on this argument, common sense and some previous evidence suggests that being in bad (health) conditions may increase people's desire to avoid doing interviews. The consequence is a selective attrition problem as a characteristic aspect of well-being data obtained in panel surveys. If this is the main conclusion from the analysis here, the implications for empirical happiness research are severe, to say the least. However, while the results indicate an attrition of afflicted people, as negative effects become weaker when differences in health-related well-being are considered, the evidence points strongly to another and probably even more intriguing explanation for the motivation-happiness link. 
By exploiting a well-known circumstance of panel surveys, the SOEP data offers a promising opportunity to implement an instrumental regression approach to identify a random group of unwilling respondents. For this purpose, identification numbers are used to determine the last year of each former interviewer while they are still doing interviews. The consequence of an interviewer dropout is for every former interviewee to be confronted necessarily with a different person than before. While the new interviewer tries to convince participants to continue in the panel, in cases of already reluctant persons, these attempts sometimes fail. This problem is well-known among survey organizers and explains why interviewer continuity is a key concern to allow for high response rates. In the present context, subsequent interviewer attrition is a suitable instrument for future interviewee attrition, as it ensures the identification of a random group of respondents who already have a lack of motivation. While interviewer changes are irrelevant to motivated participants, for some of the most unwilling participants, the exogenously given exit of the interviewer is the straw which breaks the camel's back. Because there is no other relationship between this instrument and people's well-being, the significantly negative effect revealed can only come from the low motivation of those individuals. They report being dissatisfied with their lives but they are rather dissatisfied with being interviewed.

Further support for this conclusion comes from additional regression analyses using the affective measure of people's happiness in the previous weeks. ${ }^{23}$ Such analyses do not reveal the same strong negative effects for panel quitters as in the case of the cognitive happiness measure. By controlling for health, the effects even become insignificant. This contradicts the idea that truly unhappy people are less motivated and thus leave the panel, because unhappy individuals should also be less happy according to the affective measure. It seems that only at the end of the interview when unmotivated people answer the final question on life satisfaction, the responses appear to be more negative. A feeling of being annoyed and exhausted from the lengthy interview could lead to an unpleasant situation, in which the respondent's aversion towards the survey itself provokes a negativity bias and thus a measurement error. Relevant aspects such as position of questions and length of interview imply that corresponding response artefacts can be very survey-specific, suggesting a need for research into the role of differences in survey design but also into the potential impact of respondent burden. While this factor plays no significant role in survey methodology so far, with respect to well-being measurement, the evidence here suggests that it could be relevant, just as interviewer-related effects constitute a promising avenue for further research.

\footnotetext{
${ }^{23}$ Results are available from the author upon request.
} 
With regard to the implications, it is important to note that having a causal effect of respondent motivation on self-reported happiness does not reject the alternative interpretation, according to which unhappy people are more likely to leave a panel. Instruments always identify a local effect, so the conclusion here is rather that both explanations for the link between motivation and happiness have to be taken seriously. Moreover, the direction of causality does not even matter that much in justifying the overall significance of the issue. According to the findings here, simply having more people with low willingness in a survey reduces overall happiness, whether these people are truly unhappy or whether they just report more negatively. Thus, for two exemplary panels, one with easy policies, and the other one with a tough policy to obtain as much data as possible, there is obviously a problem with the comparability of well-being data. Survey organizers can affect, knowingly or unknowingly, with their policy decisions what happiness measures reveal about a region, a cultural group, or whatever else. This needs to be considered when one compares data from different surveys.

For the research into determinants of well-being, the problems described here are extremely relevant as soon as there is a link between the factor of interest and respondent motivation. Imagine a scenario in which the researcher is interested in the impact of a potential happiness determinant, which does not actually matter to people's well-being but seems to do so according to data that is plagued by a correlation between the variable of interest and people's motivation to do the interview. Obviously, there is a strong link between people's health and their willingness to participate. Also the example of income indicates potential implications, as the happiness gap between high and low income households can be affected by differences in attrition as well as differences in response behavior. The argument of Hill and Willis (2001) who discuss the opportunity costs of participating in a survey fits in well with these considerations, as busier and more successful people are likely to be more skeptical towards investing their time into surveys. Considering these relevant points and the remaining open questions, it becomes obvious that the discussion on what is actually measured when people are questioned about happiness is going to continue, and people's motivation to do interviews is certainly one key aspect of it. 


\section{References}

Baetschmann, Gregori. Forthcoming. "Heterogeneity in the relationship between happiness and age: evidence from the German socio-economic panel.” German Economic Review.

Becketti, Sean, William Gould, Lee Lillard and Finis Welch. 1988. "The Panel Study of Income Dynamics after Fourteen Years: An Evaluation.” Journal of Labor Economics, 6: 472-92.

Behr, Andreas, Egon Bellgardt and Ulrich Rendtel. 2005. "Extent and Determinants of Panel Attrition in the European Community Household Panel.” European Sociological Review, 21: 489-512.

Burton, Jonathan, Heather Laurie, and Peter Lynn. 2006. “The Long-Term Effectiveness of Refusal Conversion Procedures on Longitudinal Surveys.” Journal of the Royal Statistical Society. Series A (Statistics in Society), 169: 459-78.

Chadi, Adrian. 2012. "I would really love to participate in your survey! Bias problems in the measurement of well-being.” Economics Bulletin, 32: 3111-19.

Chadi, Adrian. 2013a. “The Role of Interviewer Encounters in Panel Responses on Life Satisfaction.” Economics Letters, 121: 550-554.

Chadi, Adrian. 2013b. “Third Person Effects in Interview Responses on Life Satisfaction.” Journal of Applied Social Science Studies, 133: 323-333.

Conti, Gabriella, and Stephen Pudney. 2011. "Survey Design and the Analysis of Satisfaction.” Review of Economics and Statistics, 93: 1087-93.

D’Ambrosio, Conchita, and Joachim R.Frick. 2012. "Individual Wellbeing in a Dynamic Perspective.” Economica, 79: 284-302.

Ferrer-i-Carbonell, Ada, and Paul Frijters. 2004. "How important is methodology for the estimates of the determinants of happiness?” Economic Journal, 114: 641-59.

Frey, Bruno S., and Alois Stutzer. 2002. "Happiness and Economics. How the Economy and Institutions Affect Well-Being.” Princeton (N. J.): Princeton University Press.

Frijters, Paul, and Tony Beatton. 2012. "The mystery of the u-shaped relationship between happiness and age.” Journal of Economic Behavior and Organization, 82: 525-42.

Gerstorf, Dennis, Nilam Ram, Guy Mayraz, Mira Hidajat, Ulman Lindenberger, Gert G. Wagner, and Juergen Schupp. 2010. "Late-Life Decline in Well-Being Across Adulthood in Germany, the United Kingdom, and the United States: Something Is Seriously Wrong at the End of Life.” Psychology and Aging, 25: 477-85. 
Goebel, Jan, Christian Krekel, Tim Tiefenbach, Nicolas R. Ziebarth. 2013. "Natural Disaster, Policy Action, and Mental Well-Being: The Case of Fukushima.” DIW SOEPpapers on Multidisciplinary Panel Data Research 599.

Haisken-DeNew, John P., and Joachim R. Frick. 2005. “Desktop Companion to the German Socio-Economic Panel (SOEP).” DIW, Berlin.

Heffetz, Ori, and Matthew Rabin. 2013. "Conclusions Regarding Cross-Group Differences in Happiness Depend on Difficulty of Reaching Respondents.” American Economic Review, 103: 3001-21.

Hill, Daniel H., and Robert J. Willis. 2001. “Reducing Panel Attrition: A Search for Effective Policy Instruments.” Journal of Human Resources, 36: 416-38.

Hox, Joop J. 1994. "Hierarchical Regression Models for Interviewer and Respondent Effects.” Sociological Methods and Research, 22: 300-18.

Kassenboehmer, Sonja C., and John P. Haisken-DeNew. 2012. "Heresy or enlightenment? The well-being age U-shape effect is flat.” Economics Letters, 117: 235-38.

Kreuter, Frauke, Gerrit Mueller, and Mark Trappmann. 2010. “Nonresponse and Measurement Error in Employment Research: Making Use of Administrative Data.” Public Opinion Quarterly, 74: 880-906.

Kroh, Martin. 2009. "Documentation of Sample Sizes and Panel Attrition in the German Socio Economic Panel (SOEP) (1984 until 2008).” DIW Data Documentation No. 47.

Kroh, Martin. 2010. "Documentation of Sample Sizes and Panel Attrition in the German Socio Economic Panel (SOEP) (1984 until 2009).” DIW Data Documentation No. 50.

Kroh, Martin. 2012. "Documentation of sample sizes and panel attrition in the German Socio Economic Panel (SOEP) (1984 until 2011)” DIW Data Documentation No. 66.

Lipps, Oliver. 2007. “Attrition in the Swiss Household Panel.” Methoden-Daten-Analysen, 1: 45-68.

Lipps, Oliver. 2009. “Attrition of Households and Individuals in Panel Surveys.” DIW SOEPpapers on Multidisciplinary Panel Data Research 164.

Metcalfe, Robert, Nattavudh Powdthavee, and Paul Dolan. 2011. "Destruction and Distress: Using a Quasi-Experiment to Show the Effects of the September 11 Attacks on Mental Well-Being in the United Kingdom.” Economic Journal, 121: F81-F103.

Meyer, Bruce D., and James X. Sullivan. 2003. "Measuring the wellbeing of the poor using income and consumption.” Journal of Human Resources, 38: 1180-1220.

Moum, Torbjorn. 1994. "Is subjective well-being a predictor of nonresponse in broad population surveys?” Social Indicators Research, 32: 1-20. 
Nederhof, Anton. 1987. "When Neutrality is Negative: Pleasantness of Most Recent Survey Experience and Nonresponse.” Quality and Quantity, 21: 425-32.

Nicoletti, Cheti, and Franco Peracchi. 2005. “Survey Response and Survey Characteristics: Microlevel Evidence from the European Community Household Panel.” Journal of the Royal Statistical Society Series A, 168: 763-81.

Nicoletti, Cheti, Franco Peracchi, and Francesca Foliano. 2011. "Estimating Income Poverty in the Presence of Missing Data and Measurement Error.” Journal of Business and Economic Statistics, 29: 61-72.

Norris, Fran H. 1985. “Characteristics of Older Nonrespondents over Five Waves of a Panel Study.” Journal of Gerontology, 40: 627-36.

Olsen, Randall J. 2005. “The Problem of Respondent Attrition: Survey Methodology is Key.” Monthly Labor Review, 128: 63-70.

Olson, Kristen. 2013. "Do non-response follow-ups improve or reduce data quality?: a review of the existing literature.” Journal of the Royal Statistical Society Series A, 176: 129-45.

Pickery, Jan, Geert Loosveldt, and Ann Carton. 2001. “The Effects of Interviewer and Respondent Characteristics on Response Behavior in Panel Surveys: A Multilevel Approach.” Sociological Methods and Research, 29: 509-23.

Pudney, Stephen. 2011. "Perception and retrospection: The dynamic consistency of responses to survey questions on wellbeing.” Journal of Public Economic, 95: 300-10.

Schimmack, Ulrich. 2009. “Well-Being: Measuring Wellbeing in the SOEP.” Journal of Applied Social Science Studies, 129: 1-9.

Schraepler, Joerg-Peter, Juergen Schupp, and Gert G. Wagner. 2010. “Individual and Neighborhood Determinants of Survey Nonresponse.“ DIW SOEPpapers on Multidisciplinary Panel Data Research 288.

Smith, Tom W. 1984. "Estimating Nonresponse Bias with Temporary Refusals.” Sociological Perspectives, 27: 473-89.

Sobol, Marion G. 1959. “Panel Mortality and Panel Bias.” Journal of the American Statistical Association, 54: 52-68.

Stevenson, Betsey, and Justin Wolfers. 2009. “The Paradox of Declining Female Happiness.” American Economic Journal: Economic Policy, 1: 190-225.

Taylor, Mark P. 2006. “Tell Me Why I Don’t Like Mondays: investigating calendar effects on job satisfaction and well-being.” Journal of the Royal Statistical Society Series A, 169: 127-42. 
Tumen, Semih, and Tugba Zeydanli. Forthcoming. "Day-of-the-Week Effects in Subjective Well-Being: Does Selectivity Matter?” Social Indicators Research.

Uhrig, S.C. Noah. 2008. "The Nature and Causes of Attrition in the British Household Panel Survey.” ISER Working Paper Series No. 2008-05.

Wagner, Gert G., Joachim R. Frick, and Juergen Schupp. 2007. “The German SocioEconomic Panel Study (SOEP): Scope, Evolution and Enhancements.” Journal of Applied Social Science Studies, 127: 139-69.

Watson, Dorothy. 2003. "Sample Attrition between Waves 1 and 5 in the European Community Household Panel.” European Sociological Review, 19: 361-78.

Watson, Nicole, and Mark Wooden. 2004. "Sample Attrition in the HILDA Survey.” Australian Journal of Labour Economics, 7:293-308.

Watson, Nicole, and Mark Wooden. 2009. "Identifying factors affecting longitudinal survey response.” In: Methodology of Longitudinal Surveys (ed. P. Lynn), 157-82, Chichester: Wiley.

Watson, Nicole, and Mark Wooden. Forthcoming. "Re-engaging with survey nonrespondents: evidence from three household panels.” Journal of the Royal Statistical Society Series A.

Wooden, Mark, and Ning Li. Forthcoming. "Panel Conditioning and Subjective Wellbeing.” Social Indicators Research.

Wooden, Mark, and Nicole Watson. 2007. “The HILDA Survey and its Contribution to Economic and Social Research (So Far).” Economic Record, 83: 208-31.

Wunder, Christoph, and Guido Heineck. 2013. “Working time preferences, hours mismatch and well-being of couples: Are there spillovers?” Labour Economics, 24: 244-52.

Wunder, Christoph, Andrea Wiencierz, Johannes Schwarze, and Helmut Kuechenhoff. 2013. "Well-being over the life span: semiparametric evidence from British and German longitudinal data.” Review of Economics and Statistics, 95: 154-67.

Zabel, Jeffery E. 1998. “An Analysis of Attrition in the Panel Study of Income Dynamics and the Survey of Income and Program Participation with an Application to a Model of Labor Market Behavior.” Journal of Human Resources, 33: 479-506. 


\section{Appendix}

Table A1 Descriptive information on the samples used in the analysis

\begin{tabular}{|c|c|c|c|c|c|c|}
\hline & Set 1 & Set 2 & Set 3 & Set 4 & & \\
\hline Variable & Mean & Mean & Mean & Mean & Min & Max \\
\hline Primary education & 0.19 & 0.19 & 0.21 & 0.24 & 0 & 1 \\
\hline Secondary education & 0.62 & 0.62 & 0.62 & 0.62 & 0 & 1 \\
\hline Tertiary education & 0.19 & 0.20 & 0.18 & 0.14 & 0 & 1 \\
\hline Full-time employment & 0.41 & 0.40 & 0.42 & 0.39 & 0 & 1 \\
\hline Regular part-time employment & 0.10 & 0.10 & 0.10 & 0.09 & 0 & 1 \\
\hline Marginal, irregular part-time employment & 0.04 & 0.04 & 0.03 & 0.03 & 0 & 1 \\
\hline Other forms of employment & 0.03 & 0.02 & 0.03 & 0.02 & 0 & 1 \\
\hline Out of labor force & 0.43 & 0.43 & 0.42 & 0.47 & 0 & 1 \\
\hline Unemployed & 0.07 & 0.07 & 0.07 & 0.07 & 0 & 1 \\
\hline Owner of dwelling & 0.51 & 0.53 & 0.49 & 0.48 & 0 & 1 \\
\hline House in a good condition & 0.71 & 0.74 & 0.70 & 0.70 & 0 & 1 \\
\hline Some renovation needed & 0.26 & 0.24 & 0.27 & 0.26 & 0 & 1 \\
\hline Full renovation needed & 0.03 & 0.02 & 0.03 & 0.04 & 0 & 1 \\
\hline Living area & 102.51 & 104.14 & 100.46 & 97.13 & 6 & 938 \\
\hline Person needing care in household & 0.04 & 0.04 & 0.04 & 0.05 & 0 & 1 \\
\hline Number of persons in household & 2.74 & 2.74 & 2.81 & 2.72 & 1 & 14 \\
\hline Moved recently & 0.10 & 0.09 & 0.10 & 0.10 & 0 & 1 \\
\hline No children in household & 0.68 & 0.68 & 0.65 & 0.68 & 0 & 1 \\
\hline Married & 0.64 & 0.64 & 0.65 & 0.64 & 0 & 1 \\
\hline Married but separated & 0.02 & 0.02 & 0.02 & 0.02 & 0 & 1 \\
\hline Single & 0.21 & 0.21 & 0.21 & 0.19 & 0 & 1 \\
\hline Divorced & 0.07 & 0.07 & 0.06 & 0.06 & 0 & 1 \\
\hline Widowed & 0.07 & 0.07 & 0.06 & 0.08 & 0 & 1 \\
\hline Partnership & 0.80 & 0.80 & 0.80 & 0.77 & 0 & 1 \\
\hline Equalized real income & 1804.22 & 1891.08 & 1777.36 & 1675.42 & 0 & 76172 \\
\hline Age & 48.50 & 48.88 & 47.27 & 49.20 & 18 & 101 \\
\hline Female & 0.52 & 0.52 & 0.52 & 0.53 & 0 & 1 \\
\hline Degree of disability & 7.10 & 7.25 & 6.76 & - & 0 & 100 \\
\hline Nights in hospital & 1.72 & 1.66 & 1.77 & - & 0 & 360 \\
\hline Doctor visits & 2.63 & 2.54 & 2.64 & - & 0 & 99 \\
\hline Years spent in panel & 9.50 & 9.43 & 8.59 & 8.05 & 1 & 28 \\
\hline Oral interview with paper and pencil & 0.34 & 0.32 & 0.39 & 0.58 & 0 & 1 \\
\hline Oral interview with computer assistance & 0.27 & 0.30 & 0.22 & 0.28 & 0 & 1 \\
\hline Self-written with interviewer presence & 0.04 & 0.04 & 0.05 & 0.07 & 0 & 1 \\
\hline Partly oral, partly self-written interview & 0.04 & 0.05 & 0.05 & 0.07 & 0 & 1 \\
\hline Self-written without interviewer presence & 0.30 & 0.30 & 0.30 & - & 0 & 1 \\
\hline Life satisfaction & 6.99 & 6.92 & 6.97 & 7.07 & 0 & 10 \\
\hline First wave in the sample & 1995 & 2002 & 1995 & 1985 & & \\
\hline Last wave in the sample & 2011 & 2006 & 2006 & 2009 & & \\
\hline Number of observations & 249,919 & 76,236 & 176,519 & 205,034 & & \\
\hline
\end{tabular}


Table A2 Number of interviewer contacts and further descriptive information

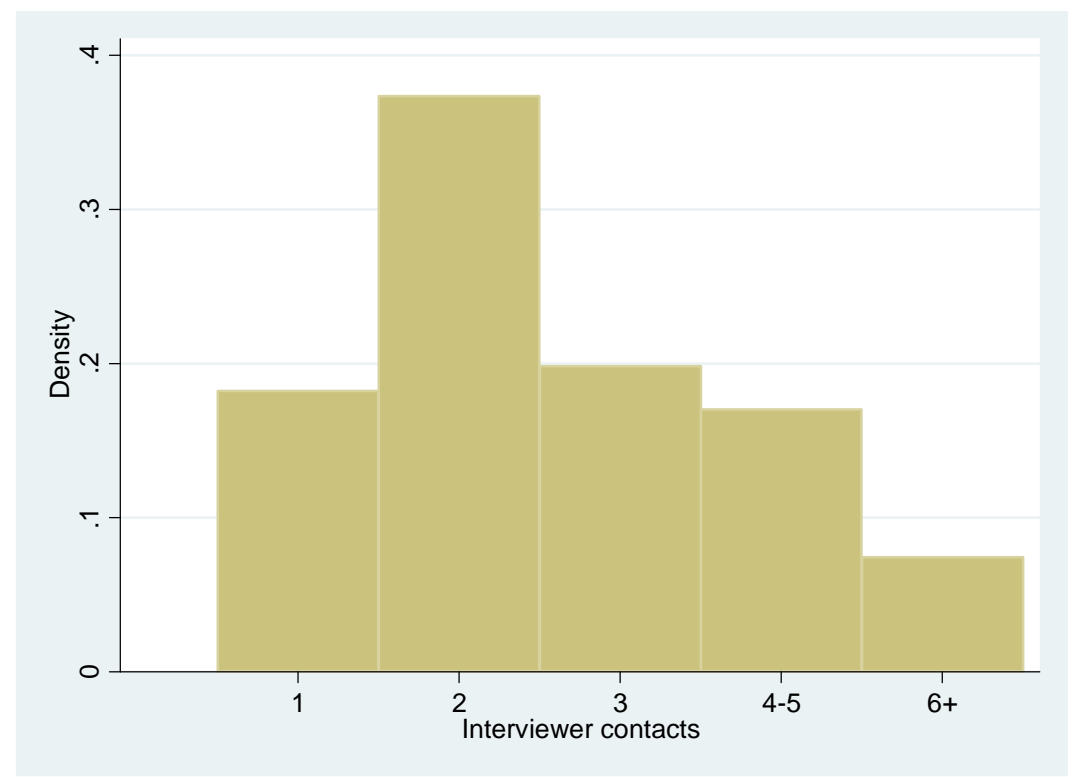

\begin{tabular}{|c|c|c|c|c|c|}
\hline Interviewer contacts & 1 & 2 & 3 & 4 or 5 & $\begin{array}{l}6 \text { and } \\
\text { more }\end{array}$ \\
\hline $\begin{array}{l}\text { Observations by } \\
\text { number of interviewer } \\
\text { contacts }\end{array}$ & (1) 45,590 & (2) 93,435 & (3) 49,643 & $\begin{array}{l}\text { (4) } 27,674 \\
\text { (5) } 14,922 \\
=42,596\end{array}$ & $\begin{array}{l}\text { (6) } 7,220 \\
\text { (7) } 4,385 \\
\text { (8) } 2,618 \\
\text { (9) } 4,432 \\
=18,655 \\
\end{array}$ \\
\hline Contact categories & 1 & 2 & 3 & 4 & 5 \\
\hline Variables & \multicolumn{5}{|c|}{ Averages per category } \\
\hline Life satisfaction & 7.07 & 6.95 & 6.98 & 6.99 & 7.00 \\
\hline Income & 1,736 & 1,750 & 1,816 & 1,881 & 2,035 \\
\hline Doctor visits & 2.72 & 2.71 & 2.58 & 2.48 & 2.44 \\
\hline Primary education & $23.5 \%$ & $19.0 \%$ & $18.4 \%$ & $17.7 \%$ & $16.2 \%$ \\
\hline Secondary education & $60.8 \%$ & $62.8 \%$ & $62.0 \%$ & $61.0 \%$ & $61.2 \%$ \\
\hline Tertiary education & $15.7 \%$ & $18.2 \%$ & $19.6 \%$ & $21.3 \%$ & $22.6 \%$ \\
\hline Out of labor force & $48.7 \%$ & $46.5 \%$ & $40.0 \%$ & $35.9 \%$ & $29.9 \%$ \\
\hline Oral interviews & $76.5 \%$ & $61.1 \%$ & $57.1 \%$ & $52.9 \%$ & $53.8 \%$ \\
\hline Year in panel & 10.55 & 9.94 & 9.05 & 8.67 & 7.74 \\
\hline
\end{tabular}

Note: The figures are based on SOEP data from 1995 to 2011 (Set 1, see Table A1). 
Table A3 Willingness to participate and further descriptive information

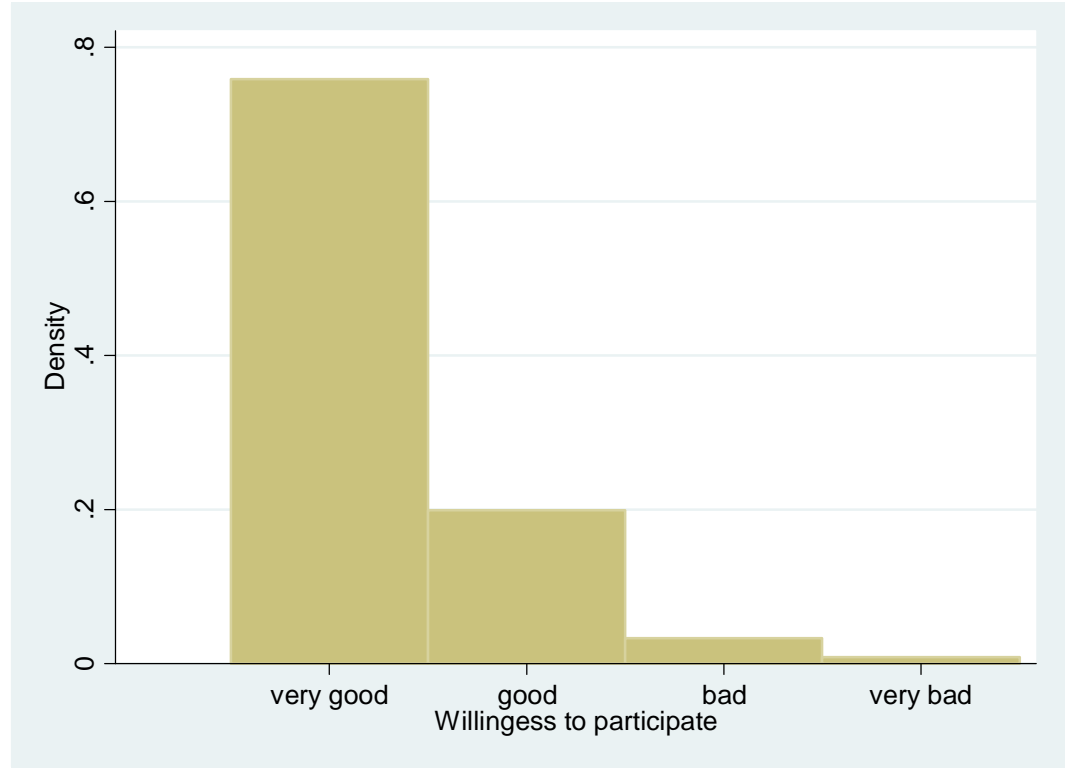

\begin{tabular}{lcccc}
\hline $\begin{array}{l}\text { Willingness to } \\
\text { participate }\end{array}$ & $\begin{array}{c}\text { 1 “very } \\
\text { good” }\end{array}$ & 2 “good” & 3 "bad” & $\begin{array}{c}4 \text { "very } \\
\text { bad” }\end{array}$ \\
\hline $\begin{array}{l}\text { Observations by level } \\
\text { of willingness }\end{array}$ & 57,877 & 15,230 & 2,509 & 620 \\
& \multicolumn{4}{c}{ Averages per category } \\
Variables & 7.03 & 6.66 & 6.31 & 6.10 \\
\hline Life satisfaction & 1,917 & 1,806 & 1,834 & 1,778 \\
Income & 2.55 & 2.54 & 2.34 & 2.39 \\
Doctor visits & $17.1 \%$ & $21.5 \%$ & $22.6 \%$ & $24.0 \%$ \\
Primary education & $62.3 \%$ & $62.1 \%$ & $60.7 \%$ & $61.9 \%$ \\
Secondary education & $20.6 \%$ & $16.4 \%$ & $16.8 \%$ & $14.0 \%$ \\
Tertiary education & $43.5 \%$ & $42.2 \%$ & $41.1 \%$ & $43.1 \%$ \\
Out of labor force & $64.2 \%$ & $56.1 \%$ & $52.1 \%$ & $44.7 \%$ \\
Oral interview & 9.54 & 9.18 & 8.56 & 8.94 \\
Year in panel & 2.69 & 3.04 & 3.77 & 4.19 \\
Interviewer contacts & & & & \\
& $18.5 \%$ & $23.3 \%$ & $28.4 \%$ & $30.6 \%$ \\
Loss in data due to & & & & \\
missing values & & & &
\end{tabular}

Note: The figures are based on SOEP data from 2002 to 2006 (Set 2, see Table A1). 
Table A4 First stage regressions for future interviewee attrition

\begin{tabular}{|c|c|c|c|c|c|}
\hline Annual interviews per interviewer: & $\min .1$ & $\min .2$ & $\min .3$ & $\min .4$ & $\min .5$ \\
\hline Last year of the interviewer & $\begin{array}{l}0.062^{* * * *} \\
(0.003)\end{array}$ & $\begin{array}{l}0.063^{* * *} \\
(0.003)\end{array}$ & $\begin{array}{l}0.063^{* * *} \\
(0.003)\end{array}$ & $\begin{array}{l}0.062^{* * *} \\
(0.003)\end{array}$ & $\begin{array}{l}0.063^{* * *} \\
(0.003)\end{array}$ \\
\hline Employment status & \multicolumn{5}{|c|}{ Reference category: full-time employment } \\
\hline $\begin{array}{l}\text { Regular part-time } \\
\text { employment }\end{array}$ & $\begin{array}{l}-0.002 \\
(0.002)\end{array}$ & $\begin{array}{l}-0.002 \\
(0.002)\end{array}$ & $\begin{array}{l}-0.002 \\
(0.002)\end{array}$ & $\begin{array}{l}-0.002 \\
(0.002)\end{array}$ & $\begin{array}{l}-0.002 \\
(0.002)\end{array}$ \\
\hline $\begin{array}{l}\text { Marginal, irregular part- } \\
\text { time employment }\end{array}$ & $\begin{array}{l}-0.002 \\
(0.003)\end{array}$ & $\begin{array}{l}-0.002 \\
(0.003)\end{array}$ & $\begin{array}{l}-0.003 \\
(0.003)\end{array}$ & $\begin{array}{l}-0.003 \\
(0.003)\end{array}$ & $\begin{array}{l}-0.003 \\
(0.003)\end{array}$ \\
\hline Other forms of employment & $\begin{array}{l}-0.002 \\
(0.003)\end{array}$ & $\begin{array}{l}-0.003 \\
(0.003)\end{array}$ & $\begin{array}{c}-0.003 \\
(0.003)\end{array}$ & $\begin{array}{l}-0.003 \\
(0.003)\end{array}$ & $\begin{array}{l}-0.003 \\
(0.003)\end{array}$ \\
\hline Out of labor force & $\begin{array}{l}0.007^{* * *} \\
(0.001)\end{array}$ & $\begin{array}{l}0.007^{* * *} \\
(0.001)\end{array}$ & $\begin{array}{l}0.007^{* * *} \\
(0.001)\end{array}$ & $\begin{array}{l}0.007^{* * * *} \\
(0.001)\end{array}$ & $\begin{array}{l}0.007^{* * *} \\
(0.001)\end{array}$ \\
\hline Unemployment & $\begin{array}{c}-0.007^{* * *} \\
(0.002)\end{array}$ & $\begin{array}{c}-0.007^{* * *} \\
(0.002)\end{array}$ & $\begin{array}{c}-0.007^{* * *} \\
(0.002)\end{array}$ & $\begin{array}{c}-0.007^{* * *} \\
(0.002)\end{array}$ & $\begin{array}{c}-0.006^{* * *} \\
(0.002)\end{array}$ \\
\hline Education & \multicolumn{5}{|c|}{ Reference category: secondary education } \\
\hline Primary education & $\begin{array}{l}0.005^{* * *} \\
(0.001)\end{array}$ & $\begin{array}{l}0.005^{* * *} \\
(0.001)\end{array}$ & $\begin{array}{l}0.005^{* * *} \\
(0.001)\end{array}$ & $\begin{array}{l}0.005^{* * *} \\
(0.001)\end{array}$ & $\begin{array}{l}0.005^{* * *} \\
(0.001)\end{array}$ \\
\hline Tertiary education & $\begin{array}{l}-0.005^{* * *} \\
(0.001)\end{array}$ & $\begin{array}{l}-0.005^{* * *} \\
(0.001)\end{array}$ & $\begin{array}{c}-0.005^{* * *} \\
(0.001)\end{array}$ & $\begin{array}{l}-0.005^{* * *} \\
(0.001)\end{array}$ & $\begin{array}{l}-0.005^{* * *} \\
(0.001)\end{array}$ \\
\hline Log equalized real income & $\begin{array}{c}-0.007^{* * *} \\
(0.001)\end{array}$ & $\begin{array}{c}-0.007^{* * *} \\
(0.001)\end{array}$ & $\begin{array}{c}-0.007^{* * *} \\
(0.001)\end{array}$ & $\begin{array}{c}-0.006^{* * *} \\
(0.001)\end{array}$ & $\begin{array}{c}-0.006^{* * *} \\
(0.001)\end{array}$ \\
\hline Owner of dwelling & $\begin{array}{c}-0.003^{* * *} \\
(0.001)\end{array}$ & $\begin{array}{c}-0.003^{* * *} \\
(0.001)\end{array}$ & $\begin{array}{c}-0.003^{* * *} \\
(0.001)\end{array}$ & $\begin{array}{c}-0.003^{* * *} \\
(0.001)\end{array}$ & $\begin{array}{c}-0.003^{* * *} \\
(0.001)\end{array}$ \\
\hline Household member needs care & $\begin{array}{l}0.047^{* * *} \\
(0.003)\end{array}$ & $\begin{array}{l}0.047^{* * *} \\
(0.003)\end{array}$ & $\begin{array}{l}0.047^{* * *} \\
(0.003)\end{array}$ & $\begin{array}{l}0.047^{* * *} \\
(0.003)\end{array}$ & $\begin{array}{l}0.047^{* * *} \\
(0.003)\end{array}$ \\
\hline Additional control variables & Yes & Yes & Yes & Yes & Yes \\
\hline Survey factors & Yes & Yes & Yes & Yes & Yes \\
\hline N (Set 4) & 189,856 & 189,307 & 188,801 & 188,351 & 187,590 \\
\hline Wald F statistic & 567.728 & 567.641 & 556.792 & 551.578 & 552.041 \\
\hline adjusted $\mathrm{R}^{2}$ & 0.036 & 0.036 & 0.036 & 0.035 & 0.035 \\
\hline \multicolumn{6}{|c|}{$\begin{array}{l}\text { Levels of statistical significance: }{ }^{*} \mathrm{p}<0.1,{ }^{* *} \mathrm{p}<0.05,{ }^{* * *} \mathrm{p}<0.01 \\
\text { Notes: The first stage results correspond to the two-stage least squares regressions in Panel C of Table } 5 \\
\text { with the endogenous dummy variable defining whether it is the respondent's last year in the panel or } \\
\text { not. Additional controls include variables for housing conditions, living area, number of persons in } \\
\text { household, no children in household, recent move, family status, partnership, age, gender, year and } \\
\text { federal state. Survey factors include the year in panel and the interview mode variables. } \\
\text { Heteroscedasticity-robust standard errors are in parentheses. }\end{array}$} \\
\hline
\end{tabular}

